\title{
GPS Seismology for a moderate magnitude earthquake: Lessons learned from the analysis of the 31 October $2013 \mathrm{M}_{\mathrm{L}} 6.4$ Ruisui (Taiwan) earthquake
}

\author{
Huang-Kai Hung ${ }^{1}$, Ruey-Juin Rau ${ }^{2, *}$, Elisa Benedetti ${ }^{3}$, Mara Branzanti ${ }^{3}$, Augusto Mazzoni ${ }^{3}$, \\ Gabriele Colosimo ${ }^{3}$, Mattia Crespi ${ }^{3}$
}

\author{
${ }^{1}$ National Science and Technology Museum, Kaohsiung, Taiwan \\ ${ }^{2}$ Department of Earth Sciences, National Cheng Kung University, Tainan, Taiwan \\ ${ }^{3}$ Geodesy and Geomatics Division, Department of Civil, Building and Environmental Engineering, University of Rome \\ "La Sapienza", Rome, Italy
}

Article history

Received February 25, 2017; accepted June 11, 2017.

Subject classification:

High-rate GPS, Measurements and monitoring, Instruments and techniques, Ground motion, GPS Seismology .

\begin{abstract}
The 31 October $2013 M_{L} 6.4$ Ruisui earthquake was well recorded by twelve $50-\mathrm{Hz}$, four $20-\mathrm{Hz}$ and thirteen $1-\mathrm{Hz}$ GPS receivers, and twenty-five strong motion stations located within the epicentral distance of $90 \mathrm{~km}$ in eastern Taiwan. Kinematic positioning solutions estimated by four GNSS software (TRACK, RTKLIB, GIPSY, VADASE) are used to derive the seismic waveforms and the co-seismic displacements for this event; strong motion accelerometers are used to verify the capability of high rate GPS to detect seismic waves generated by this earthquake. Results show that the coordinate repeatability of the GPS displacements time series are $\sim 6 \mathrm{~mm}$ and $\sim 20 \mathrm{~mm}$ standard deviation in the horizontal and vertical components respectively, after applying spatial filtering. The largest co-seismic displacement derived from high-rate GPS is nearly 15 centimeter at $5 \mathrm{~km}$ northeast of the epicenter. $S$ waves and surface waves are successfully detected by motions of high-rate GPS and double-integrated accelerometers within the $15 \mathrm{~km}$ epicentral distance. For the first time twelve $50-\mathrm{Hz}$ and four $20 \mathrm{~Hz}$ GPS observations for seismological study were used and analyzed in Taiwan; a clear benefit was evidenced with regard to the seismic waves features detection, with respect to the $1-\mathrm{Hz}$ GPS data, so that ultra-high rate $(>1-\mathrm{Hz})$ observations can compensate the sparse coverage of seismic data, provided proper monuments for the GPS permanent stations are realized. Spectra analysis between co-located GPS and strong motion data further suggests that the optimal sampling rate for high-rate GPS Seismology study is $5 \mathrm{~Hz}$. The 2013 Ruisui Taiwan earthquake recorded by the high-rate GPS permanent stations network in Taiwan demonstrates the benefits of GPS Seismology for a moderate size earthquake at a local scale.
\end{abstract}

\section{Introduction}

High-rate GPS has become an important sensor for the seismic wave detections and earthquake warning systems for moderate and large earthquakes. The true ground displacements retrieved from the processing of high-rate GPS observations provide precise seismic waveforms to identify the wave property, the arrival time of the body waves and the surface wave [Kouba 2003, Larson et al. 2003, Bock et al. 2004, Langbein and Bock 2004, Kouba 2005, Ohta et al. 2006, Larson et al. 2007, Bilich et al. 2008, Larson and Miyazaki 2008, Miyazaki and Larson 2008, Davis and Smalley 2009, Larson 2009, Shi et al. 2010, Avallone et al. 2011, Ohta et al. 2012, Branzanti et al. 2013, Li et al. 2013, Benedetti et al. 2014, Li et al. 2014a,b]. For large disastrous earthquakes, such as the $2004 \mathrm{Su}-$ matra and the 2011 Tohoku-Oki earthquakes, highrate GPS gives the possibility to provide information about fault rupture processes, focal mechanism determinations, and tsunami warning and monitoring in near real-time [Ohta et al. 2006, Blewitt et al. 2009, Crowell et al. 2009, Colosimo et al. 2011a,b, Ohta et al. 2012], also considering the remarkable advantage of the no-clipping and no-tilting features with respect to the strong motion and broadband seismometers [Bilich et al. 2008, Zheng et al. 2012]. Significant surface wave propagation and attenuation are observed by regional dense Continuous GPS Permanent Stations (CGPSs) network [Davis and Smalley 2009, 
Grapenthin and Freymueller 2011, Hung and Rau 2013].

However, the traditional sampling interval of the high-rate GPS $(1-\mathrm{Hz})$ cannot always describe the seismic waveforms completely due to waveforms of higher frequency in near-field earthquakes [Avallone et al. 2011]. Efficient sampling rate of the position time series for the waveforms monitoring are controlled by the Nyquist-Shannon sampling theorem, which states that the recording sampling rate should be twice larger (in practice, it should be at least four times larger) than the main frequency for the interesting signals. Some moderate earthquakes recorded in near-field with $5-\mathrm{Hz}$ and $10-\mathrm{Hz}$ sampling rate demonstrate the benefit of the very-high-rate GPS for the waveforms recover [Avallone et al. 2011, Zheng et al. 2012, Lou et al. 2014]. On the other hand, differently from the reconstruction of the entire waveforms, it was showed that co-seismic displacements can be accurately detected by the combination of the 1-Hz GPS solutions and co-located accelerometer [Bock et al. 2011, Melgar et al. 2013].

As regard the present study, since 2010 a dense CGPSs network of nearly four hundred sites has been established at $10-20 \mathrm{~km}$ spacing in Taiwan from various institutions. About 250 stations established mainly by Central Weather Bureau (CWB), Central Geological Survey (CGS) and National Land Surveying and Mapping Center (NLSC) are available for high-rate GPS recording for both geodetic and geophysical applications. The receivers installed more recently are characterized by a larger storage and a higher sampling rate capacity [Yeh et al. 2012, Hung and Rau 2013].

These features were exploited to collect GPS observations at high-rate and very high sampling rate for this study, where we used 1-Hz, 20-Hz and 50-Hz CGPS observations for the investigations on the moderate Ruisui earthquake ( $\mathrm{M}_{\mathrm{L}}$ 6.4) occurred on 31th October, 2013 in eastern Taiwan, which was already object of other seismological researches [e.g., Lee at al. 2014, Wen et al. 2016]. In details, thanks to the availability of both CGPS network, broadband seismometers and strong motion accelerometers, the goals of the work was to develop a deep comparison about the solutions supplied by these different instruments (also considering different GPS software) as regards seismic waveforms and the co-seismic displacements, and to verify the capability of high-rate GPS to detect body waves and surface waves.

In section 2 the used data and software are introduced; in section 3 the main results are presented and discussed; in section 4 some conclusions are outlined.

\section{Data and method}

CGPS dual-frequency observations at $1-\mathrm{Hz}, 20-\mathrm{Hz}$ and $50-\mathrm{Hz}$ sampling rate were collected to estimate the epoch-by-epoch position time series during the 2013 Ruisui earthquake in eastern Taiwan (Figure 1) for the seismic waveforms and co-seismic displacements monitoring. Detailed information for the four $20-\mathrm{Hz}$ GPS stations from National Cheng Kung University and twelve 50-Hz GPS stations from Central Weather Bureau, including the types of the GPS receivers and antennas are listed in Table 1 . Observations of broadband seismometers (BB) were collected from BATS (Broadband Array in Taiwan for Seismology, http:// bats.earth.sinica.edu.tw/) and strong motion data were collected from the Central Weather Bureau, Taiwan. Note that some near-field seismic waveforms obtained from broadband seismometer stations HGSD and YULB are clipped (Figure 2).

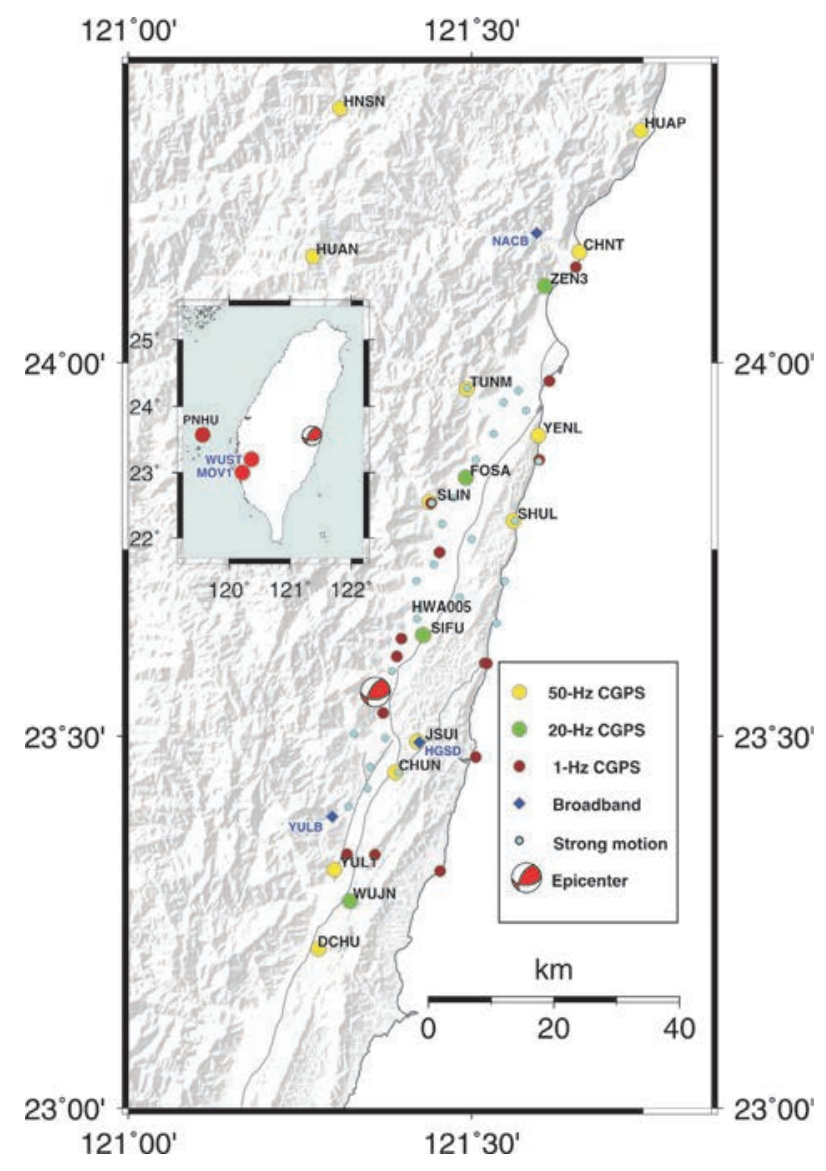

Figure 1. Map of CGPS and seismic stations around the epicenter of the 2013 Ruisui earthquake, eastern Taiwan. Focal mechanism of the Ruisui earthquake is shown in lower-hemisphere projection. Yellow, green and red dots denote CGPS at 50- $\mathrm{Hz}, 20-\mathrm{Hz}$ and $1-\mathrm{Hz}$ frequency sampling, respectively, cyan dots are strong motion stations; blue diamonds are broadband seismic stations. Stations MOV1 and WUST located at the western Taiwan are selected as the base stations for the composition of the common mode filters. Station PNHU was the fixed station for the GPS processing using software TRACK. 


\begin{tabular}{|c|c|c|c|c|c|c|}
\hline CGPS & $\begin{array}{c}\text { Longitude } \\
\text { (degree) }\end{array}$ & $\begin{array}{l}\text { Latitude } \\
\text { (degree) }\end{array}$ & Receiver type & Antenna type & Monument type & $\begin{array}{c}\text { Original } \\
\text { sampling rate }\end{array}$ \\
\hline ZEN3 & 121.6067 & 24.1025 & $\begin{array}{l}\text { TRIMBLE } \\
\text { NETR8 }\end{array}$ & TRM55971.00 & ROOF & $20-\mathrm{Hz}$ \\
\hline FOSA & 121.4917 & 23.8463 & $\begin{array}{l}\text { TRIMBLE } \\
\text { NETR8 }\end{array}$ & TRM55971.00 & ROOF & $20-\mathrm{Hz}$ \\
\hline SIFU & 121.4297 & 23.6362 & $\begin{array}{l}\text { TRIMBLE } \\
\text { NETR8 }\end{array}$ & TRM55971.00 & ROOF & $20-\mathrm{Hz}$ \\
\hline WUJN & 121.3229 & 23.2788 & $\begin{array}{l}\text { TRIMBLE } \\
\text { NETR8 }\end{array}$ & TRM55971.00 & ROOF & $20-\mathrm{Hz}$ \\
\hline HUAP & 121.7463 & 24.3106 & $\begin{array}{l}\text { TRIMBLE } \\
\text { NETR8 }\end{array}$ & TRM55971.00 & ROOF & $50-\mathrm{Hz}$ \\
\hline CHNT & 121.6573 & 24.1482 & $\begin{array}{l}\text { TRIMBLE } \\
\text { NETR8 }\end{array}$ & TRM55971.00 & ROOF & $50-\mathrm{Hz}$ \\
\hline HNSN & 121.3079 & 24.3398 & $\begin{array}{l}\text { TRIMBLE } \\
\text { NETR9 }\end{array}$ & TRM57971.00 & GROUND & $50-\mathrm{Hz}$ \\
\hline HUAN & 121.2687 & 24.1423 & $\begin{array}{l}\text { TRIMBLE } \\
\text { NETR9 }\end{array}$ & TRM57971.00 & GROUND & $50-\mathrm{Hz}$ \\
\hline TUNM & 121.4922 & 23.9647 & $\begin{array}{l}\text { TRIMBLE } \\
\text { NETR9 }\end{array}$ & TRM57971.00 & GROUND & $50-\mathrm{Hz}$ \\
\hline YENL & 121.5972 & 23.9024 & $\begin{array}{l}\text { TRIMBLE } \\
\text { NETR9 }\end{array}$ & TRM57971.00 & GROUND & $50-\mathrm{Hz}$ \\
\hline SLIN & 121.4381 & 23.8133 & $\begin{array}{l}\text { TRIMBLE } \\
\text { NETR9 }\end{array}$ & TRM57971.00 & GROUND & $50-\mathrm{Hz}$ \\
\hline SHUL & 121.5608 & 23.7884 & $\begin{array}{l}\text { TRIMBLE } \\
\text { NETR9 }\end{array}$ & TRM57971.00 & GROUND & $50-\mathrm{Hz}$ \\
\hline JSUI & 121.4206 & 23.4934 & $\begin{array}{l}\text { TRIMBLE } \\
\text { NETR9 }\end{array}$ & TRM57971.00 & GROUND & $50-\mathrm{Hz}$ \\
\hline CHUN & 121.3892 & 23.4516 & $\begin{array}{l}\text { TRIMBLE } \\
\text { NETR9 }\end{array}$ & TRM57971.00 & GROUND & $50-\mathrm{Hz}$ \\
\hline DCHU & 121.2773 & 23.2144 & $\begin{array}{l}\text { TRIMBLE } \\
\text { NETR9 }\end{array}$ & TRM57971.00 & GROUND & $50-\mathrm{Hz}$ \\
\hline YUL1 & 121.3002 & 23.3213 & $\begin{array}{l}\text { TRIMBLE } \\
\text { NETR9 }\end{array}$ & TRM57971.00 & GROUND & $50-\mathrm{Hz}$ \\
\hline
\end{tabular}

Table 1. Information of 50-Hz and 20-Hz CGPS stations used.

GPS epoch-by-epoch displacements were estimated from phase measurements in kinematic positioning [Hofmann-Wellenhof et al. 2006], following three different approaches and using four GNSS software:

- Differential Positioning (DP), using TRACK software [Herring 2009]. The reference station used, PNHU, as shown in Figure 1 is located $200 \mathrm{~km}$ west of the epicenter, outside the deforming region with stable coordinate time series.

- Precise Point Positioning (PPP), using GIPSY-OASIS II [Zumberge et al. 1997] and RTKLIB software [Takasu 2011]; precise orbits and clock error corrections were generated by Jet Propulsion Laboratory for GIPSY-OASIS II, and from final International GNSS Service (IGS) solutions for RTKLIB.

- Variometric approach, using VADASE software [Colosimo et al. 2011a, Branzanti et al. 2013, Benedetti et al. 2014]; here solutions were obtained in post-processing mode, but in order to simulate its real-time capabilities standard broadcast orbits and clocks were used.

To reduce the position errors due to the multipath effect in the cycles of the sidereal day, modified sidereal filtering (MSF) was constructed and applied to the original positions [Choi et al. 2004, Hung and Rau 2013]. Subsequently, a spatial filter (SP) were applied to each position time series to remove the common-mode error resulted from unmodeled effects during data processing [Wdowinski et al. 1997, Bilich et al. 2008, Yin and Wdowinski 2013], where the stations MOV1 and WUST (Figure 1) located about $150 \mathrm{~km}$ away from the epicenter are used to construct the spatial filter. These two stations were checked for their data quality and if there is any disturbance induced by the earthquake. The displacements after applying spatial filtering are analyzed for the investigations of their precisions and waveform propagations. The main features and parameter settings for the processing with all GNSS software are listed in Table 2. 

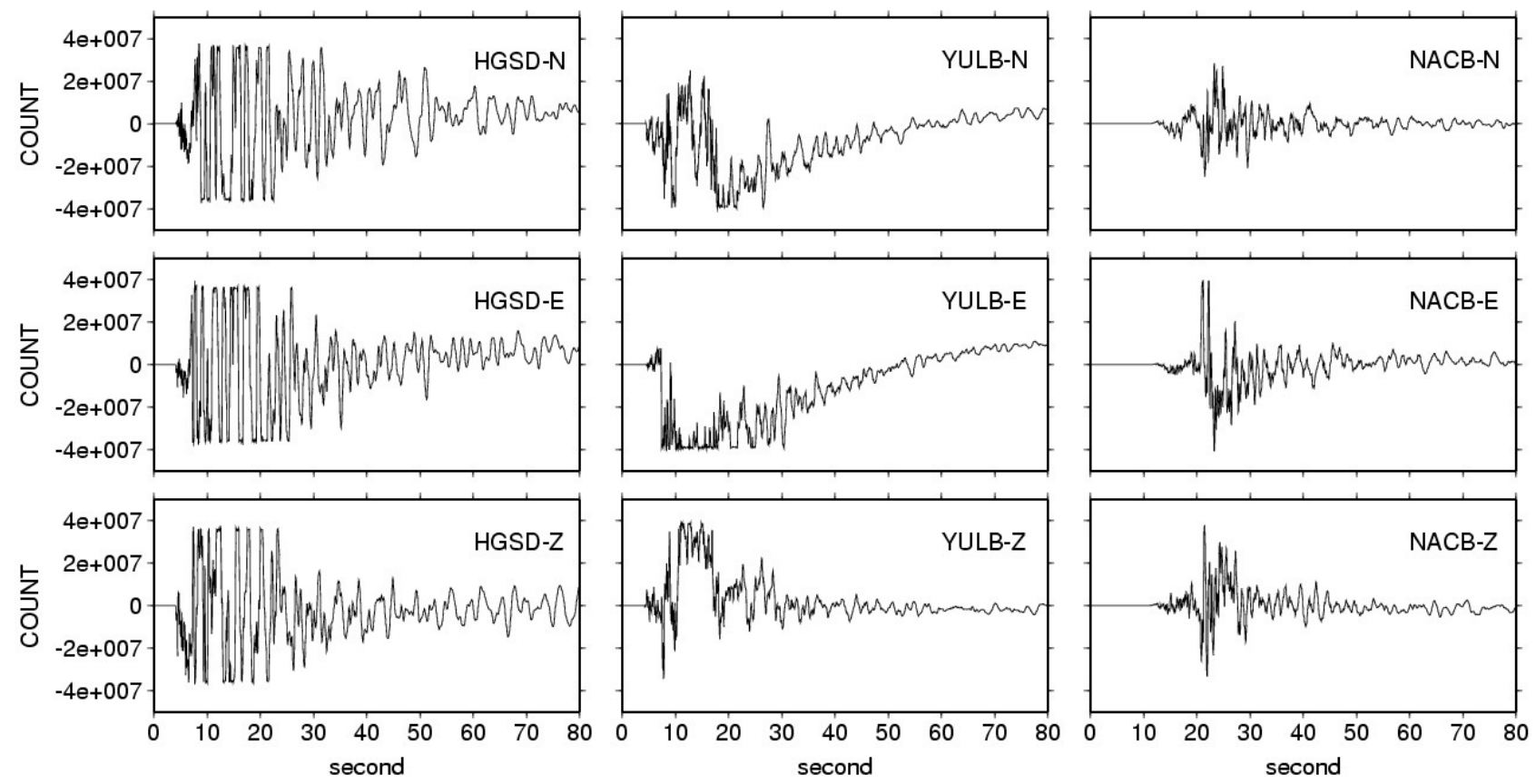

Figure 2. Seismic waveforms generated from broadband seismometer station HGSD, YULB, and NACB in all the three components in Ruisui earthquake. Waveforms are clipped for stations HGSD (all the three components) and YULB (East and North components).

As regard the strong motion data (SMT), the 200-Hz sampling rate observations were transformed into displacements by double integration using software TSPP established by USGS [Boore 2010]. Baseline corrections were applied to SMT using a zeroth-order-correction by removing the mean of 8 -seconds segment before the earthquake origin time. Instrument responses were removed by deconvolution of
3.1 Seismic waveforms vs GPS observations with different sampling rate

To investigate the reconstruction of the seismic waveforms from GPS at different sampling rate, we firstly considered the effectiveness of the waveforms sampling interval at 0.2-, 1-, 5-, 10-, and 20-Hz. Figure 3a shows that the clear seismic shaking occurs after 5 seconds with respect to the earthquake origin time

\begin{tabular}{lcccc}
\hline Software & Strategy & Orbits & Clocks & Observation interval \\
\hline TRACK & Differential & Precise (IGS) & - & $2 \mathrm{~h}$ \\
GIPSY & PPP & Precise (JPL) & JPL 30 sec & $2 \mathrm{~h}$ \\
RTKLIB-PPP & PPP & Precise (IGS) & CODE 5 sec & $2 \mathrm{~h}$ \\
VADASE-L3 & Variometric & Broadcast & Broadcast & $2 \mathrm{~min}$ \\
\hline
\end{tabular}

Table 2. Main feature of different adopted GPS processing strategies.

the low-cut $(0.02 \mathrm{~Hz})$ and high-cut $(100 \mathrm{~Hz})$ filters in the acceleration space. For the broadband observations, the displacements were generated by single integration after removing the instrument response given the poles and zeros of the instrument [Hung and Rau 2013].

Therefore, a comparison among the different GNSS software, the strong motion and broadband integrated solutions was possible at the level of epoch-by-epoch displacements.

\section{Results and discussion}

Several aspects were investigated considering the results obtained using different software, with different observations sampling rate and at different CGPSs. Hereafter the main results are presented and discussed. for all the ground motion time series. The sampling rate at $0.2-\mathrm{Hz}$ and $1-\mathrm{Hz}$ truncate the seismic signals and cannot retrieve the complete waveforms; also $1-\mathrm{Hz}$ sampling rate apparently is not high enough to retrieve the complete patterns of the ground vibrations. As a matter of fact, spectral analysis show that the major energy in this earthquake is located at $0-1.5 \mathrm{~Hz}$ interval (Figure $3 \mathrm{~b}$ ). This is also why waveforms retrieved from $10-\mathrm{Hz}$ and $20-\mathrm{Hz}$ sampling rates (Figure 3a) indicate similar ground motions, therefore in the following we refer to the $10-\mathrm{Hz}$ GPS solutions only instead of the original sampling rate. Notice that the frequency spectra of sampling rate of $5 \mathrm{~Hz}, 10 \mathrm{~Hz}$ and $20 \mathrm{~Hz}$ become flat at the frequency lower than about $2.5 \mathrm{~Hz}$. 
(a)

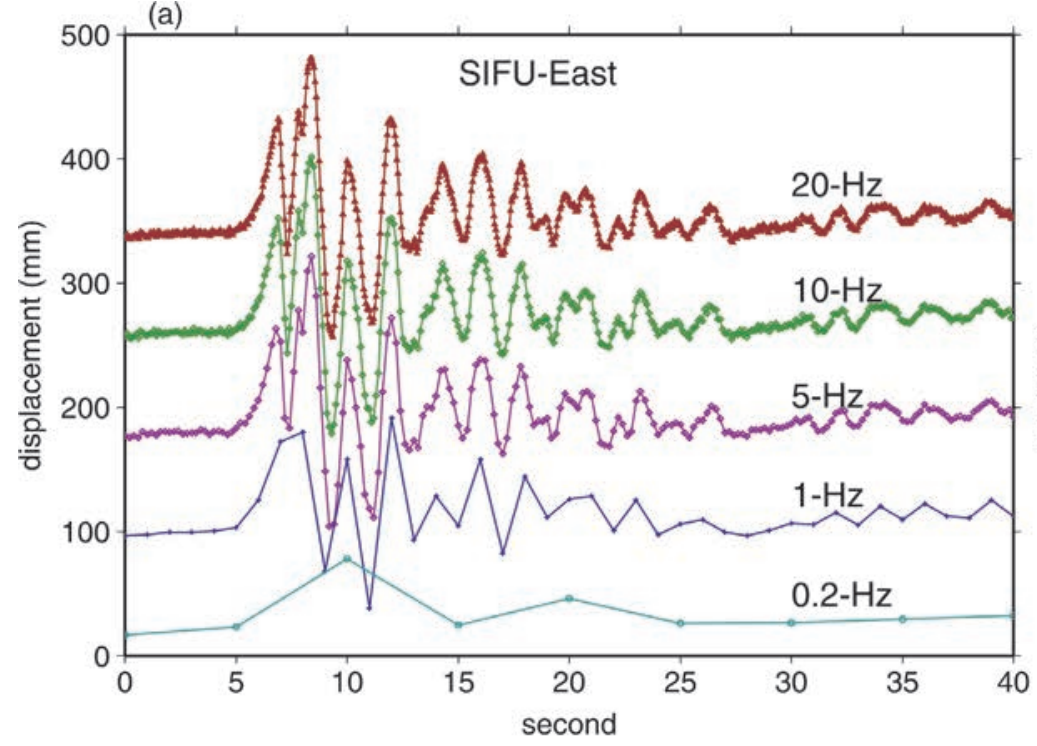

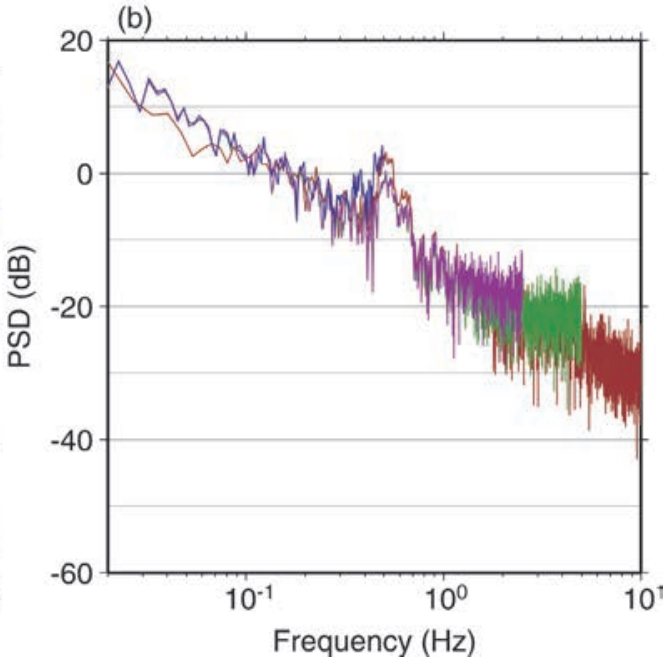

Figure 3. (a) Displacements time series at CGPS SIFU in sampling interval from 0.2 to $20 \mathrm{~Hz}$ in the East component using software VADASE $(\mathrm{t}=0 \mathrm{sec}$ is the earthquake origin time). (b) Power spectral density (PSD) of the displacements time series at the station SIFU with the 20-Hz (brown), 10-Hz (green), 5- $\mathrm{Hz}$ (purple) and 1- $\mathrm{Hz}$ (blue) sampling interval in the East component; the major energy content of the seismic waveforms is located at $0-1.5 \mathrm{~Hz}$.

\subsection{Software comparison}

The seismic displacements derived from $10-\mathrm{Hz}$ observations at CGPS SIFU for software TRACK, GIPSY-OASIS II, RTKLIB and VADASE are displayed in Figure 4, as an example. The coordinate repeatability of these $10-\mathrm{Hz}$ solutions for the 20 seconds interval before the earthquake was estimated for the four software (TRACK, GIPSY-OASIS II, RTKLIB and VADASE (Table 3)). It is clear that similar waveforms were obtained with the different software at CGPS SIFU in all the three components during 5-30 seconds after the earthquake origin time (Figure 4). VADASE software, whose solutions were obtained using broadcast ephemeris and clocks only, was able to reconstruct waveform features similar to those of other software using precise orbits and clocks information. Albeit with

\begin{tabular}{lccc}
\hline Software & $\boldsymbol{\sigma}_{\mathbf{n}}(\mathbf{m m})$ & $\boldsymbol{\sigma}_{\mathbf{e}}(\mathbf{m m})$ & $\boldsymbol{\sigma}_{\mathbf{u}}(\mathbf{m m})$ \\
\hline TRACK & 5.5 & 3.1 & 10.9 \\
RTKLIB & 3.1 & 8.0 & 10.9 \\
GIPSY & 3.0 & 6.7 & 13.0 \\
VADASE & 13.7 & 11.3 & 20.7 \\
\hline
\end{tabular}

Table 3. Coordinate repeatability of resampled 10-Hz GPS using various software (computed from 20 seconds before and to the origin time).

its 2 times larger uncertainties (Table 3), solutions with VADASE software confirmed the approach reliability. Spectral analysis also indicates similar results in the frequency domain among the solutions obtained with the four different software (Figure 5). Similar results

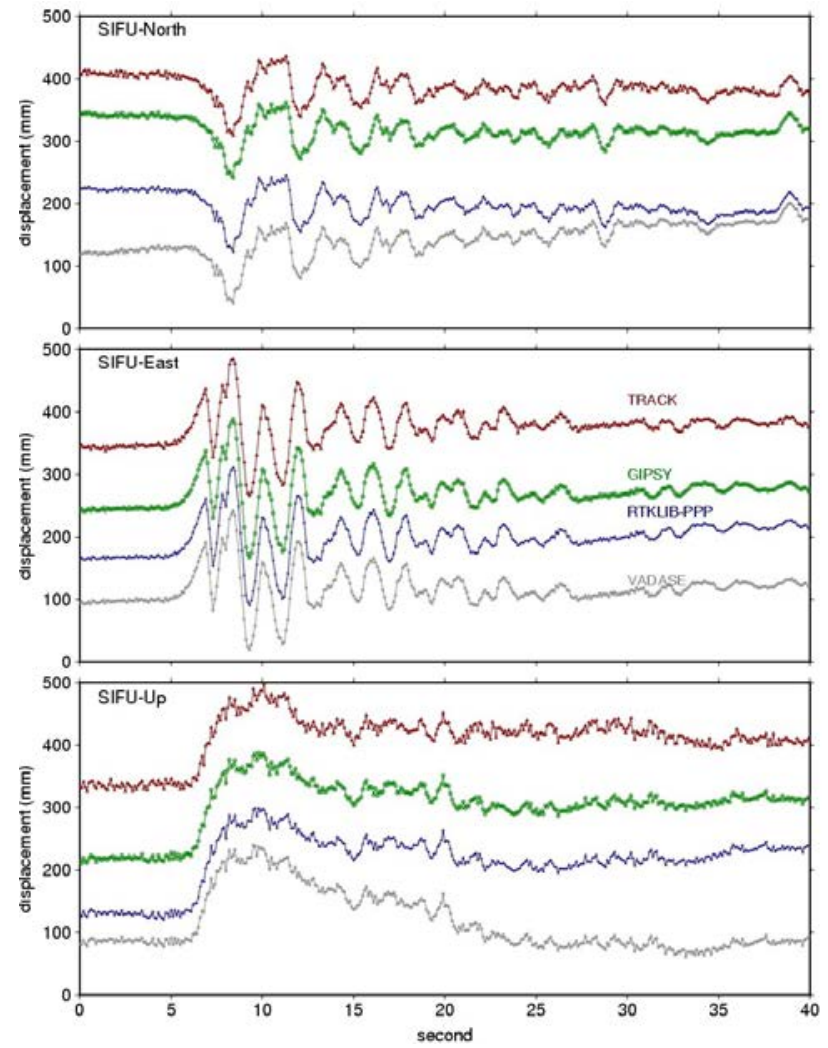

Figure 4. Displacements time series at CGPS SIFU generated from software TRACK (brown), GIPSY (green), RTKLIB in the PPP solution (blue), and VADASE (grey) in all the three components.

confirming the good agreement among the software were obtained for other CGPSs. It has to be recalled that here all the solutions were obtained in post-processing mode, but all the approaches are able to supply real-time solutions, albeit with different technological 

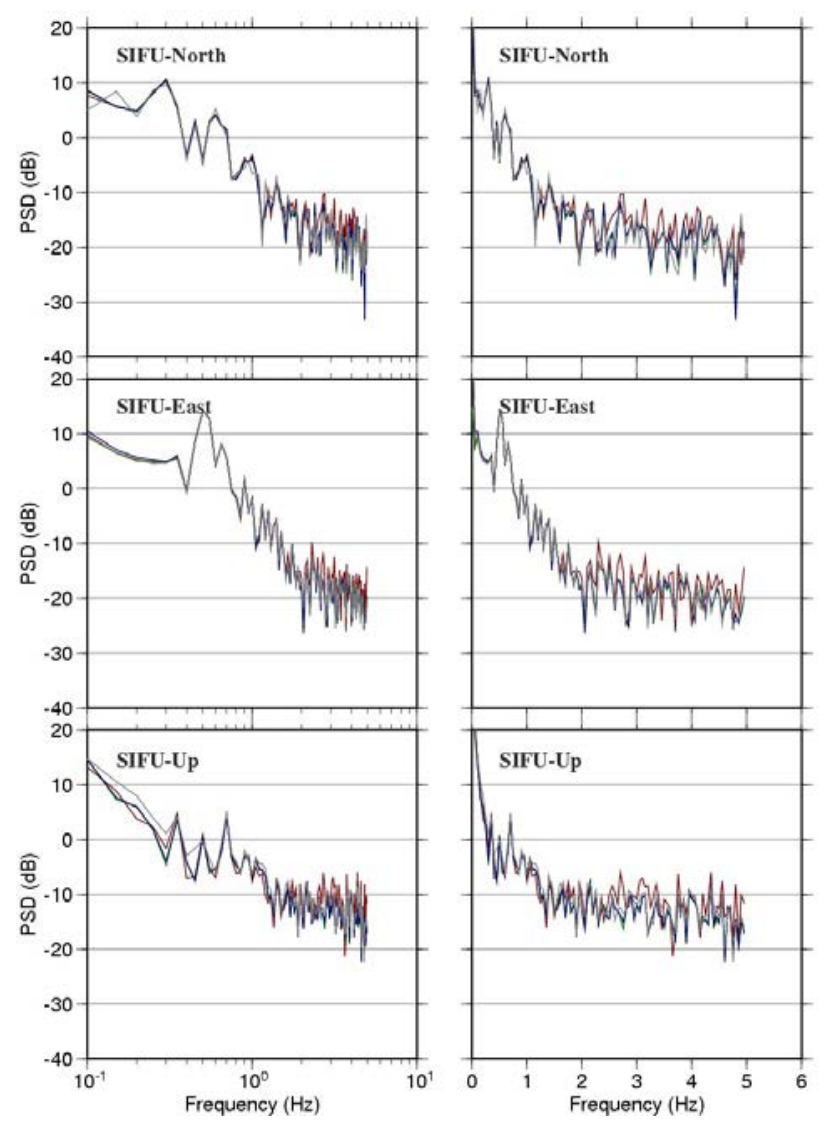

Figure 5. Power spectral density (PSD) of the displacements time series at CGPS SIFU generated from software TRACK (brown), GIPSY (green), RTKLIB in the PPP solution (blue), and VADASE (grey) in all the three components.

requirements (GNSS receiver features, types of satellite orbits and clocks) [Bock et al. 2000, Colosimo et al. 2011, Li et al. 2014a,b]. The filtered displacement time series after applying spatial filters (SP) composed by stations MOV1 and WUST indicate apparent consistency (Figure 6). Larger motion drifts occur for VADASE solutions, which can be reduced after applying SP. The noise reduction effect are similar for the four software, except for the higher drifts for TRACK solutions, which may be resulted from longer baseline estimations (around $200 \mathrm{~km}$ ).

\subsection{GPS vs strong motion}

Figure 6 shows that the ground motions have excellent agreement between GPS and co-located double-integrated SMT data (Table 4). Correlation coefficients

\begin{tabular}{lcccc}
\hline GPS & SMT & $\begin{array}{c}\text { Latitude } \\
\text { (degree) }\end{array}$ & $\begin{array}{c}\text { Longitude } \\
(\text { degree })\end{array}$ & $\begin{array}{c}\text { Inter-distance } \\
(\mathbf{k m})\end{array}$ \\
\hline CHNT & HWA025 & 24.16 & 121.66 & 1.6 \\
SLIN & HWA020 & 23.81 & 121.44 & 0.4 \\
SHUL & HWA001 & 23.79 & 121.56 & 0.2 \\
CHUN & HWA037 & 23.45 & 121.39 & 0.4 \\
\hline
\end{tabular}

Table 4. Global information of the approximately co-located CGPS and strong motion stations (average).

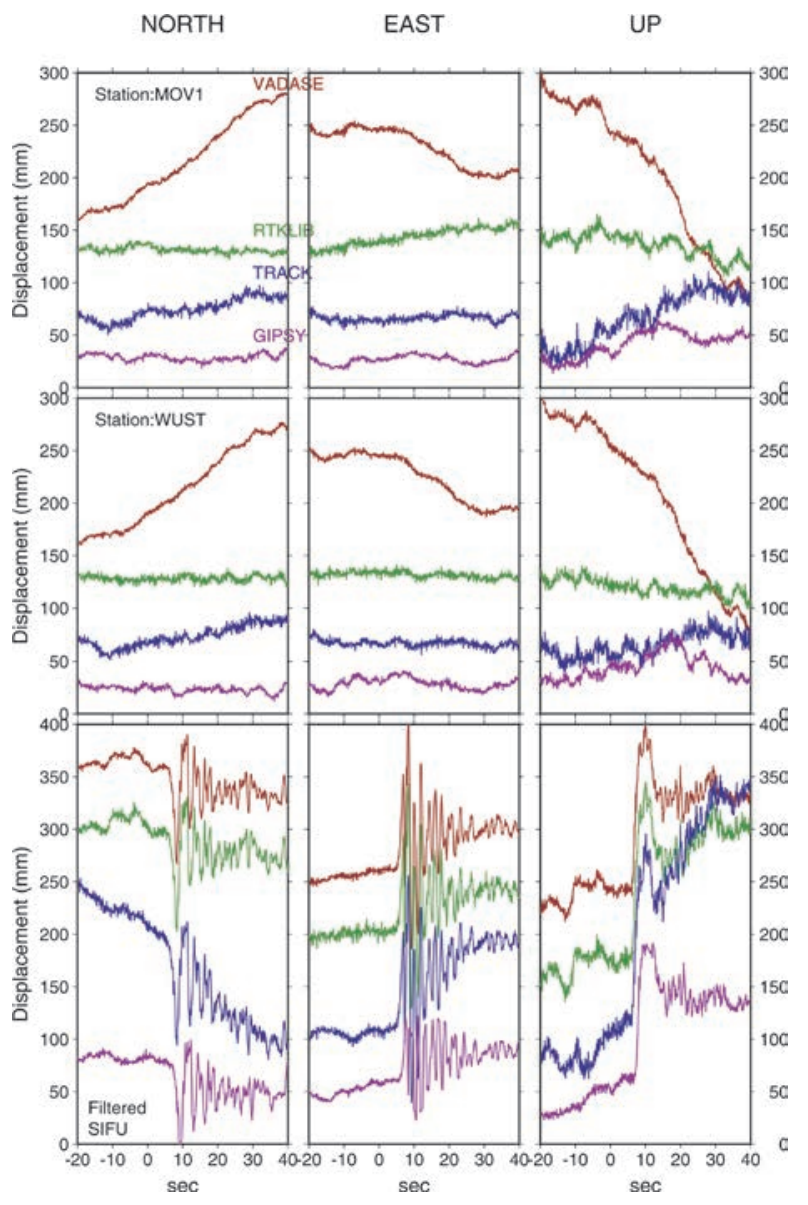

Figure 6. GPS displacement time series retrieved after applying spatial filters using four GPS software. Stations MOV1 and WUST are used to compose spatial filters. Brown, green, blue, and purple lines show the motions of MOV1 and WUST calculated using VADASE, RTKLIB, TRACK, and GIPSY, respectively. Time series of station SIFU after applying spatial filtering are shown at the bottom.

in horizontal components between both measurements are 0.6-0.75 after applying 0.2-Hz high-pass filter (Figure 7). The need to high-pass the SMT data is to remove the effects of low frequency bias, introducing trends after integration. Spectral analysis shows that both observations have similar patterns in the frequency span of $0.3-2.0 \mathrm{~Hz}$ (Figure 8). The ground motion sensitivity limit is about $-20 \mathrm{~dB}$ for GPS observations for a frequency higher than about $2.5 \mathrm{~Hz}$, and above this frequency the noises of GPS are always larger than those of the corresponding SMT data (Figure 8 ). This suggests that a minimum sampling rate of $5 \mathrm{~Hz}$ is required for optimum high-rate GPS observations. Energy in SMT solutions at the frequency larger than $2.5-\mathrm{Hz}$ decreases rapidly and remains at the flat noise level for the GPS results. The noise level in the Up component is always larger than those in the horizontal component, especially for the station far away from the epicenter, such as station CHNT (Figures 

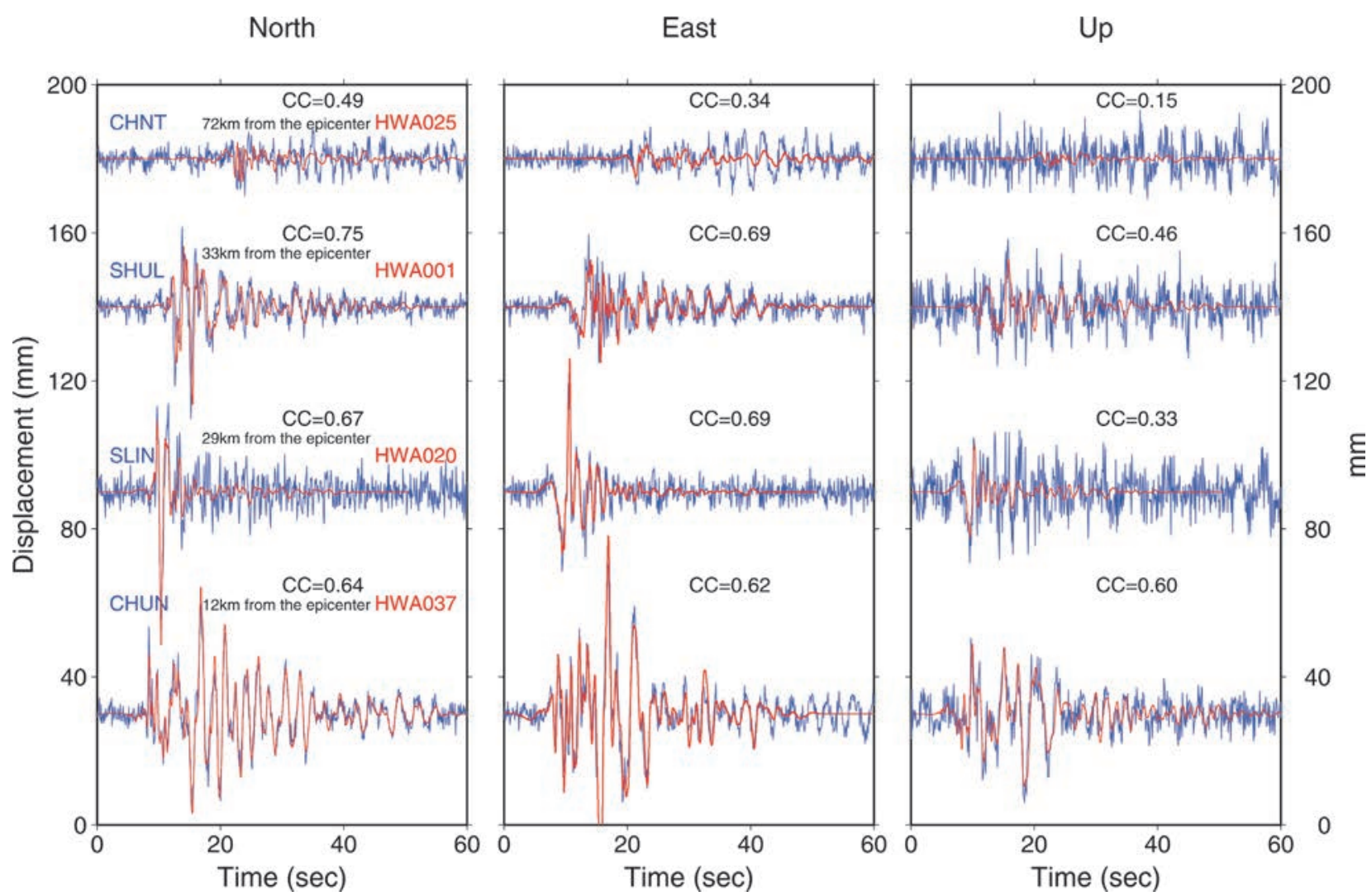

Figure 7. Displacements time series in all the three components from resampled 10-Hz CGPS and co-located strong motion data after double integration and application of $0.2-\mathrm{Hz}$ high-pass filter. $\mathrm{CC}$ is the correlation coefficient.

7 and 8). Spectrum coherence analysis between 60 seconds time series of GPS and SMT station pairs indicate large coherencies of near 1 in the frequency span of $0.3-2 \mathrm{~Hz}$, especially for the station pairs SLIN-HWA020 and SHUL-HWA001 in the horizontal components (Figure 9).

\subsection{Waves propagation and attenuation}

Displacements for all the high-rate GPS of $10-\mathrm{Hz}$ and $1-\mathrm{Hz}$ sampling interval in the transverse and radial components show clear directivity effects (Figure 10). Apparent group velocities of about $4.0 \mathrm{~km} / \mathrm{s}$ are shown in both components for waves propagating northward. The wave amplitudes in the northern direction are apparently larger than those toward South. Seismic wave are hardly detected at the epicenter distance larger than 90 kilometer. Displacements of 1-Hz GPS (green line) improve the spatial coverage of the network for the estimation of the apparent group velocity (Figure 10).

\subsection{Co-seismic displacements}

Co-seismic displacements for each CGPS in all the three components were determined by the difference between the coordinate averages of 100 150 seconds after the earthquake origin time and

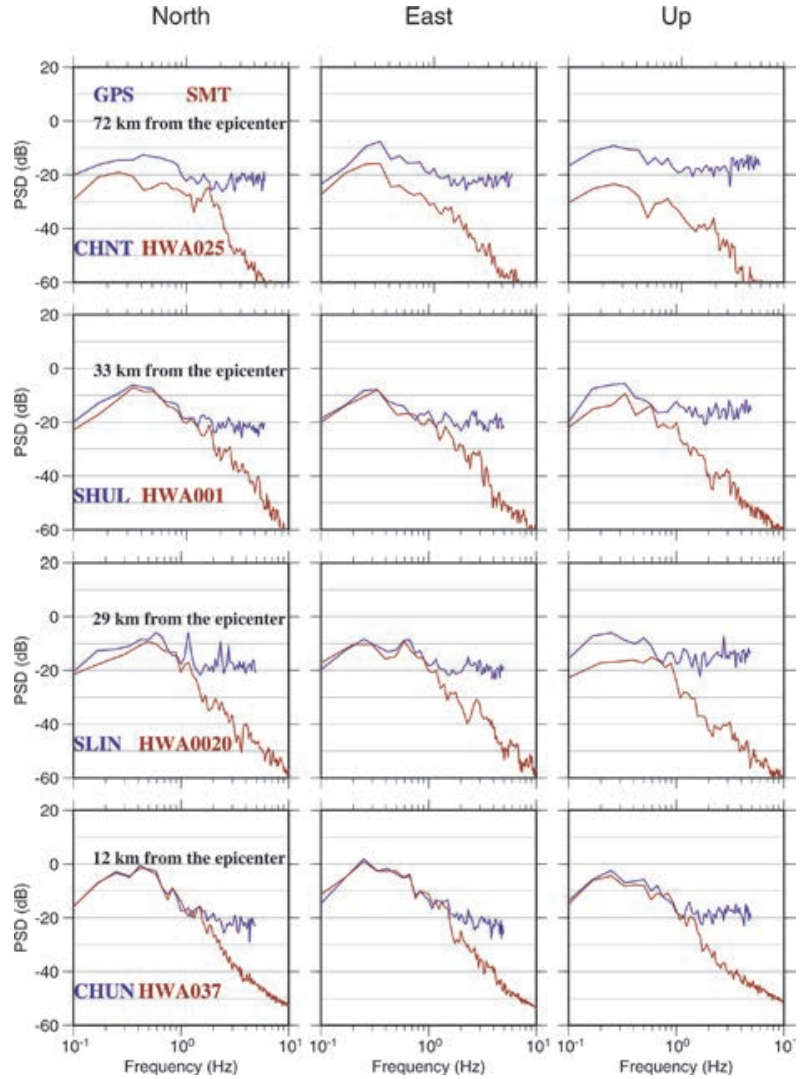

Figure 8. Power spectral density (PSD) of the displacements time series from CGPS and co-located strong motion data after double integration and application of $0.2-\mathrm{Hz}$ high-pass filter. Blue is GPS, and red is SMT. 


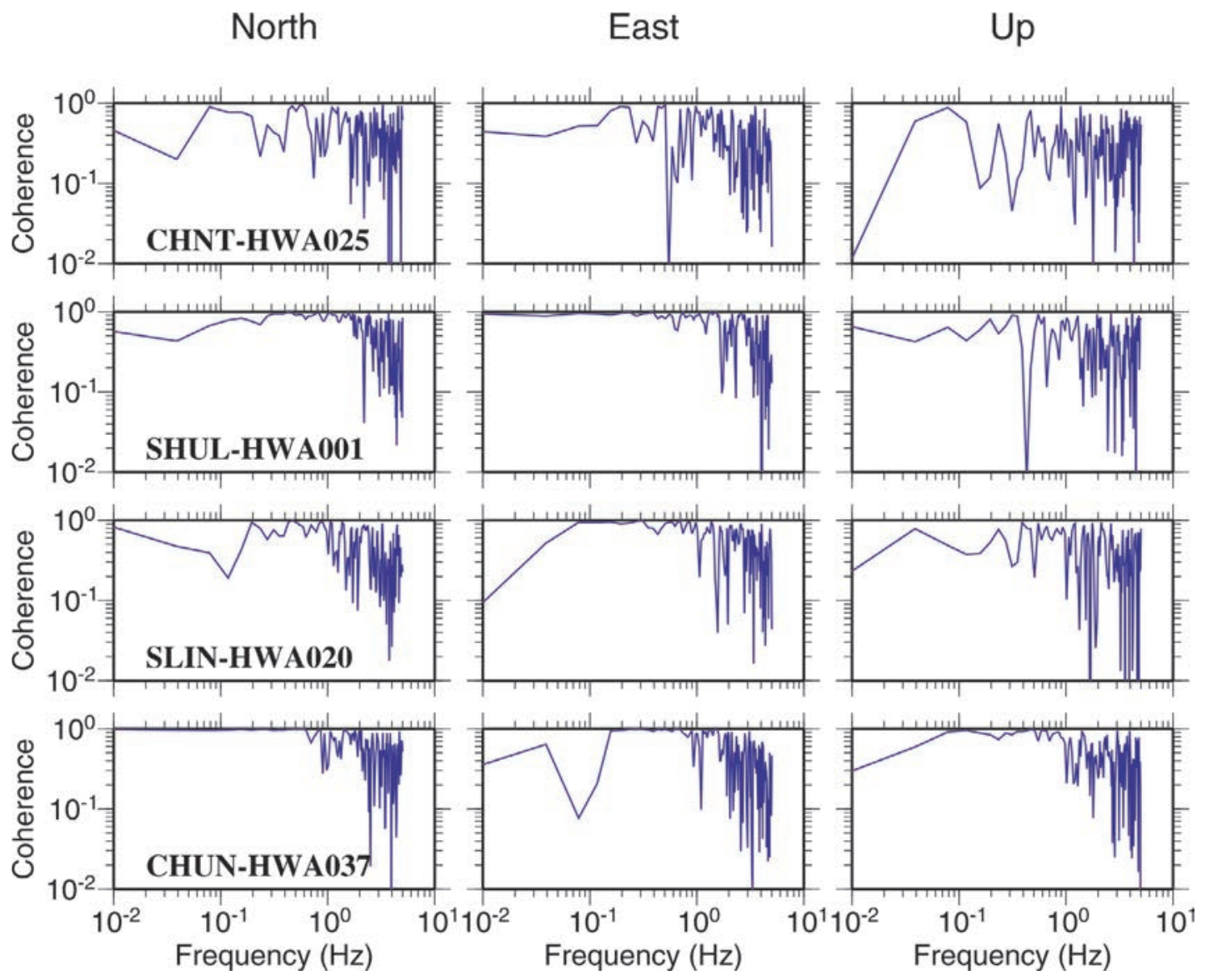

Figure 9. Spectrum coherence in three components for the 60 seconds times series of station pairs (Figure 7) of 10-Hz GPS and co-located strong motion data after double integration and 0.2-Hz high-pass filter.

50 seconds before the earthquake. Ground motions were estimated from the 1-Hz high-rate GPS measurements just using software TRACK software, considering the proven good agreement among the four software; after applying the spatial filtering, around 2-12 centimeters co-seismic displacements at the stations within $5-40 \mathrm{~km}$ to the epicenter were
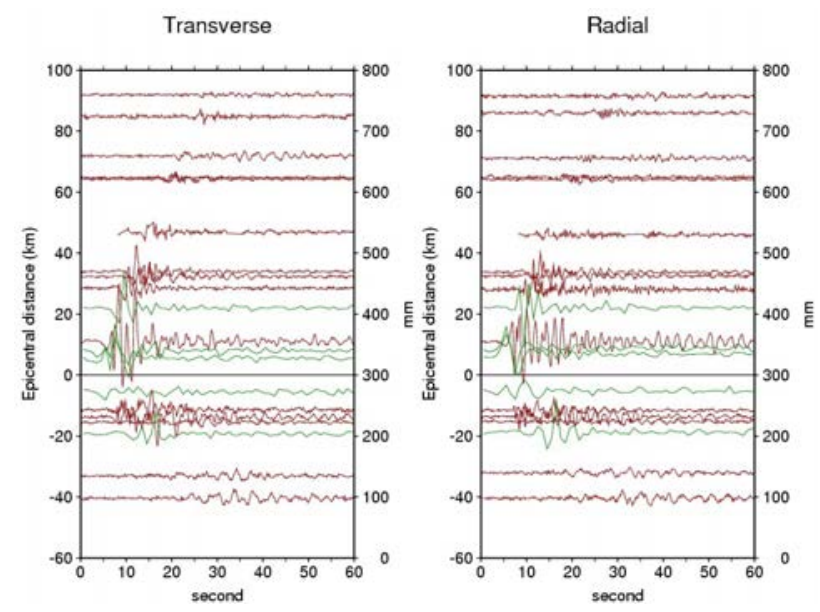

Figure 10. Resampled $10-\mathrm{Hz}$ displacements (red line) and $1-\mathrm{Hz}$ displacements (green line) time series in the transverse and radial components with respect to the epicentral distance (an epicentral distance is positive northward with respect to the epicenter). detected (Figure 11a and Figure 11b). The precision of the co-seismic displacements are $3 \mathrm{~mm}$ and $5 \mathrm{~mm}$ in the horizontal and vertical components, respectively.

Figure $12 \mathrm{a}$ and $12 \mathrm{~b}$ show that the largest co-seismic displacements are located about $10 \mathrm{~km} \mathrm{NE}$ of the epicenter. For the four GPS stations with noticeable co-seismic displacement (horizontal component > $16 \mathrm{~mm}$ ), we compare their co-seismic displacements estimated from $1-\mathrm{Hz}$ and daily solutions (the coordinate average of 3 days after the earthquake subtract the 3 days average before the earthquake), respectively (Figure 12a and 12b). We found that the two stations (DSIN and GUFU) closer to the epicenter have larger co-seismic displacements estimated from the daily solutions than those derived from $1-\mathrm{Hz}$ solutions, while the other two stations (SIFU and FENP) showing similar results. This indicates that the nearer stations may have early post-seismic deformation. On the other hand, peak ground displacement (PGD) of the stations show the largest value of about $200 \mathrm{~mm}$ for both horizontal and vertical components (Figure $12 \mathrm{a}$ and $12 \mathrm{~b}$ ), and PGD distributions indicate clear attenuations of the amplitude with respect to the epicentral distances. 


\subsection{Ground vs. roof monuments}

We selected three pairs of the CGPS to investigate how the waveforms computation is affected by the different types (ground, roof) of monuments (Table 5, Figure 13). Ground-type monuments are established by four
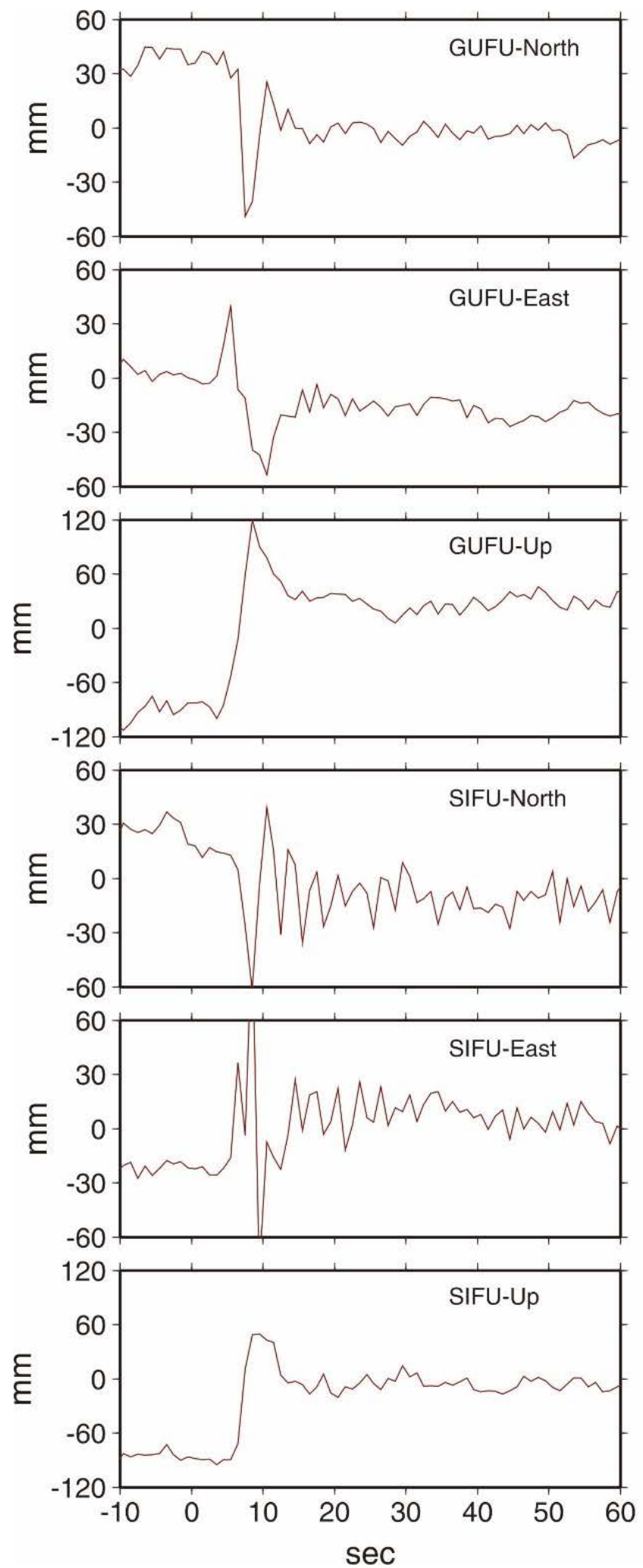

steel piles on the ground, and the roof-type antenna are mounted on the roof using the single-steel piles (Figure 13). Results show that the waveforms (1-Hz sampling rate) have no significant differences for pair height difference lower than 10 meters. Pair DSIN-GUFU, around 40

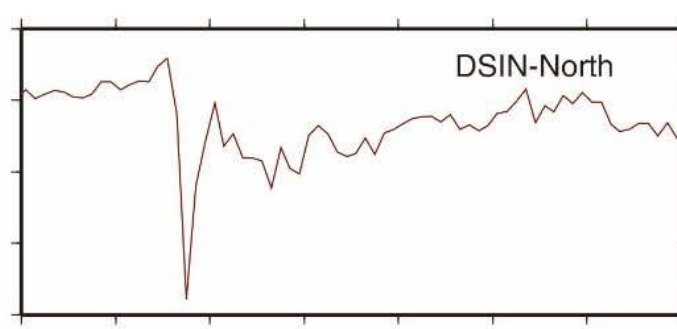

60 30

0 ह $-30$ $-60$ 60

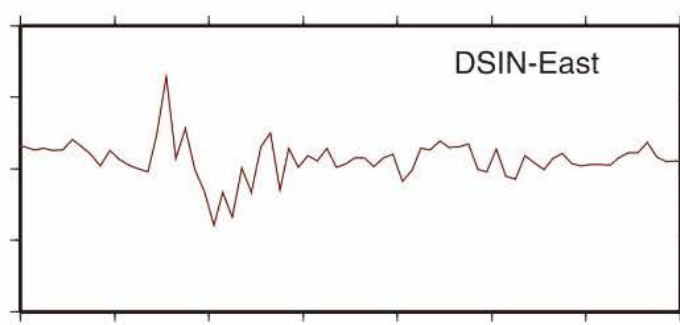

30

$0 \xi$ $-30$ $-60$

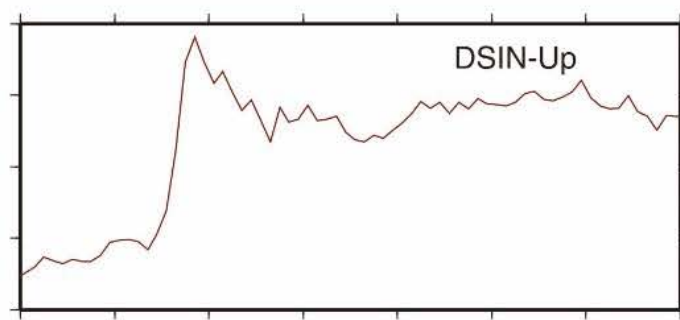
120 60

0 है $-60$ $-120$

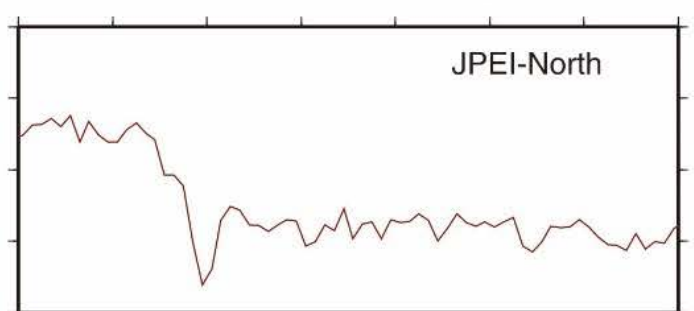

30

0 ह $-30$ $-60$

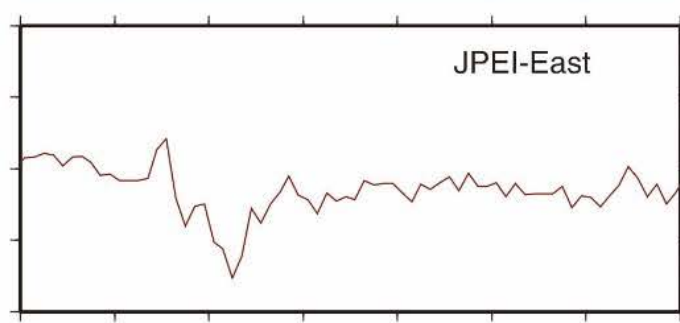

60

30

0 ह $-30$ $-60$

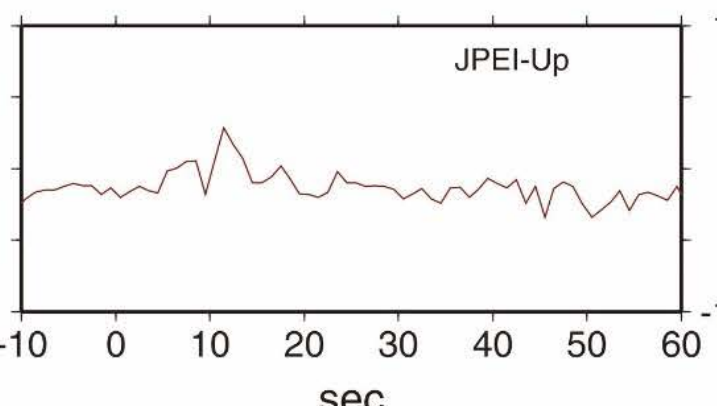

Figure 11a. Time series highlighting the co-seismic displacements of 1-Hz CGPSs using TRACK software, after applying the spatial filtering in all the three components. 
meter height difference, has around $3 \mathrm{~cm}$ motion difference at 7-10 second after the earthquake origin time (Figure 14). Since the inter-station distance of DSIN-GUFU is around 3 kilometers, so that the waveform differences can be due also to this different location.
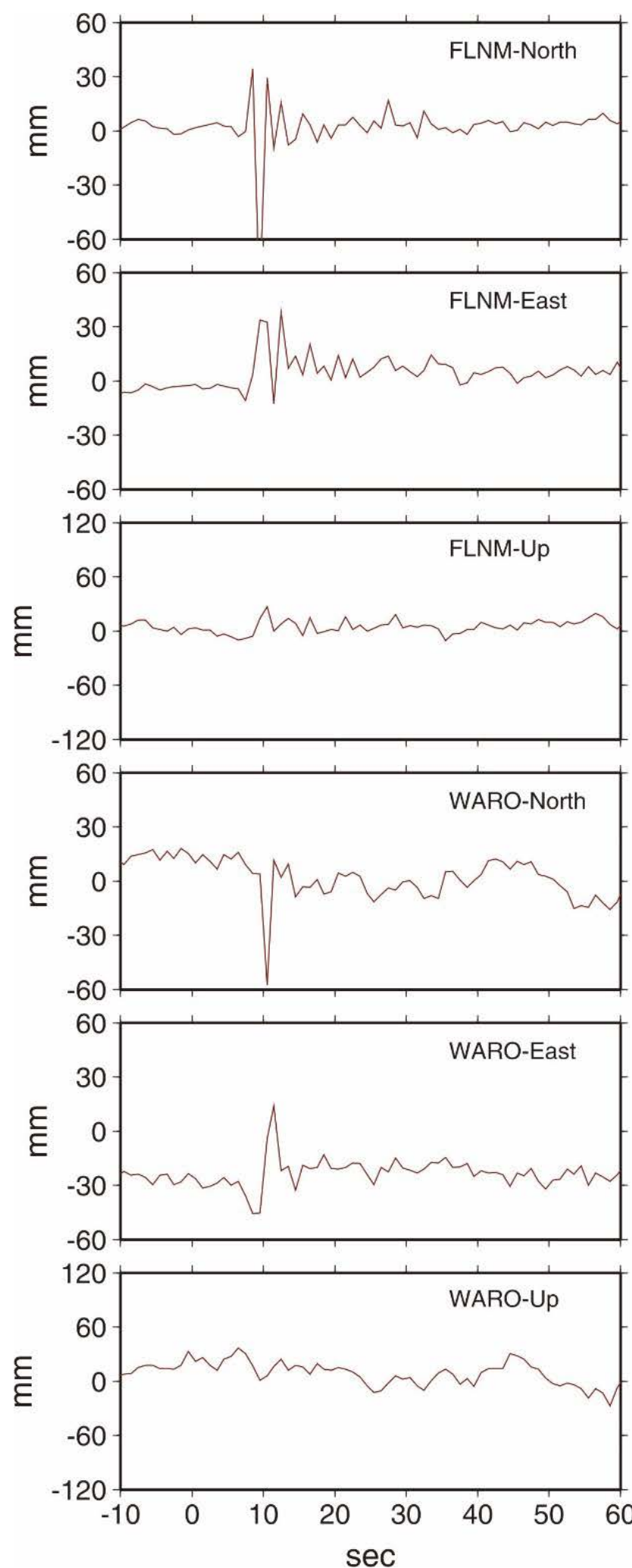

3.7 Trapped waves in the Longitudinal Valley

Seismic waveforms obtained from CGPSs and SMTs display regional inconsistence in eastern Taiwan. Seismic waveforms triggered by the Ruisui earthquake are significantly different among stations in the Central Range

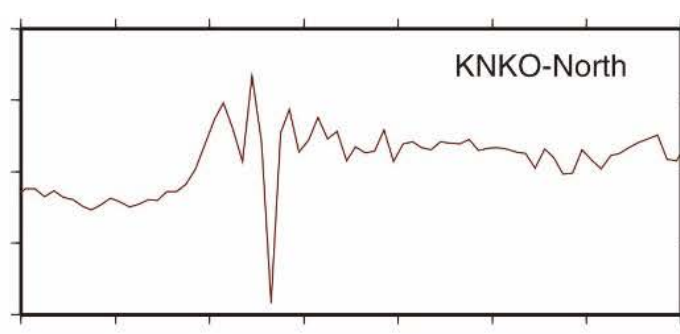

60 30

0 ह $-30$ $-60$

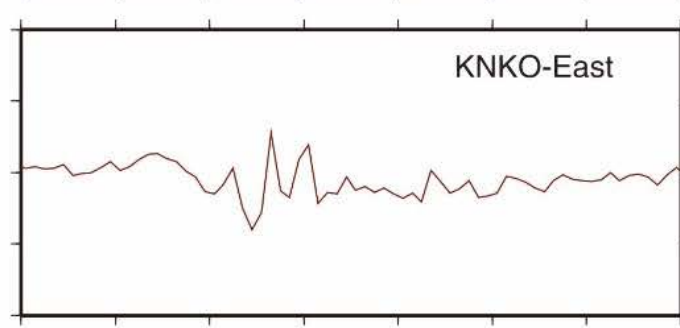

60

30

0 ह $-30$ $-60$

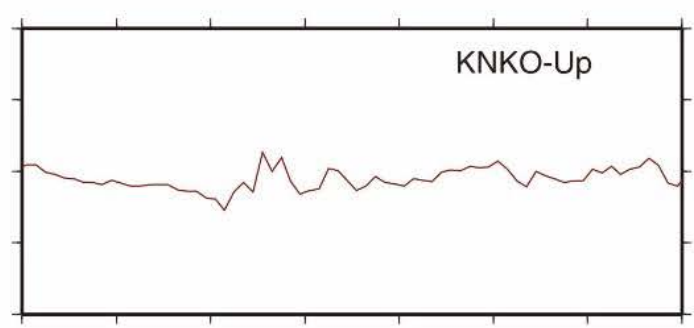
120 60

0 ह $-60$ $-120$

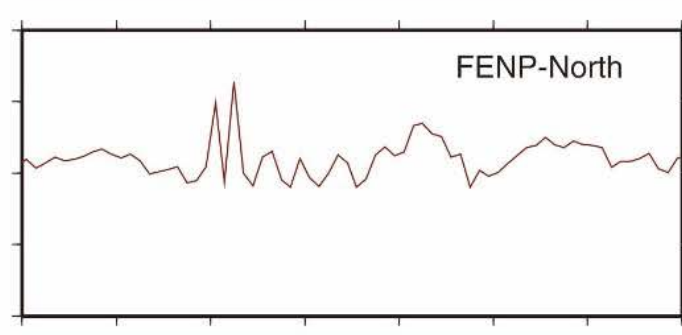

60

30

0 ह $-30$ $-60$

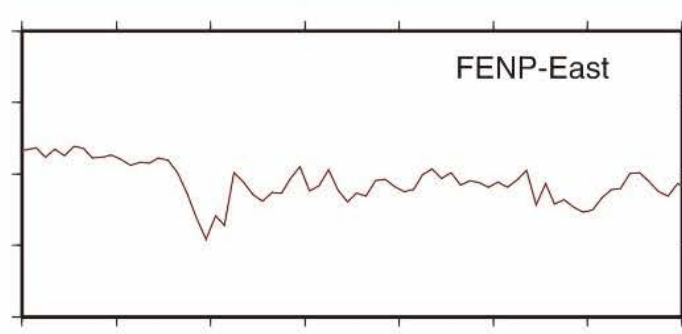
60 30 0 ह $-30$ $-60$

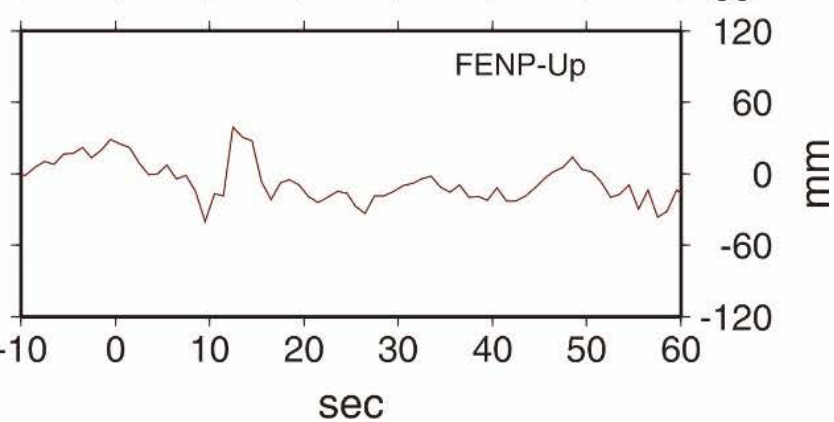

Figure 11b. Time series highlighting the co-seismic displacements of 1-Hz CGPSs using TRACK software, after applying the spatial filtering in all the three components. 

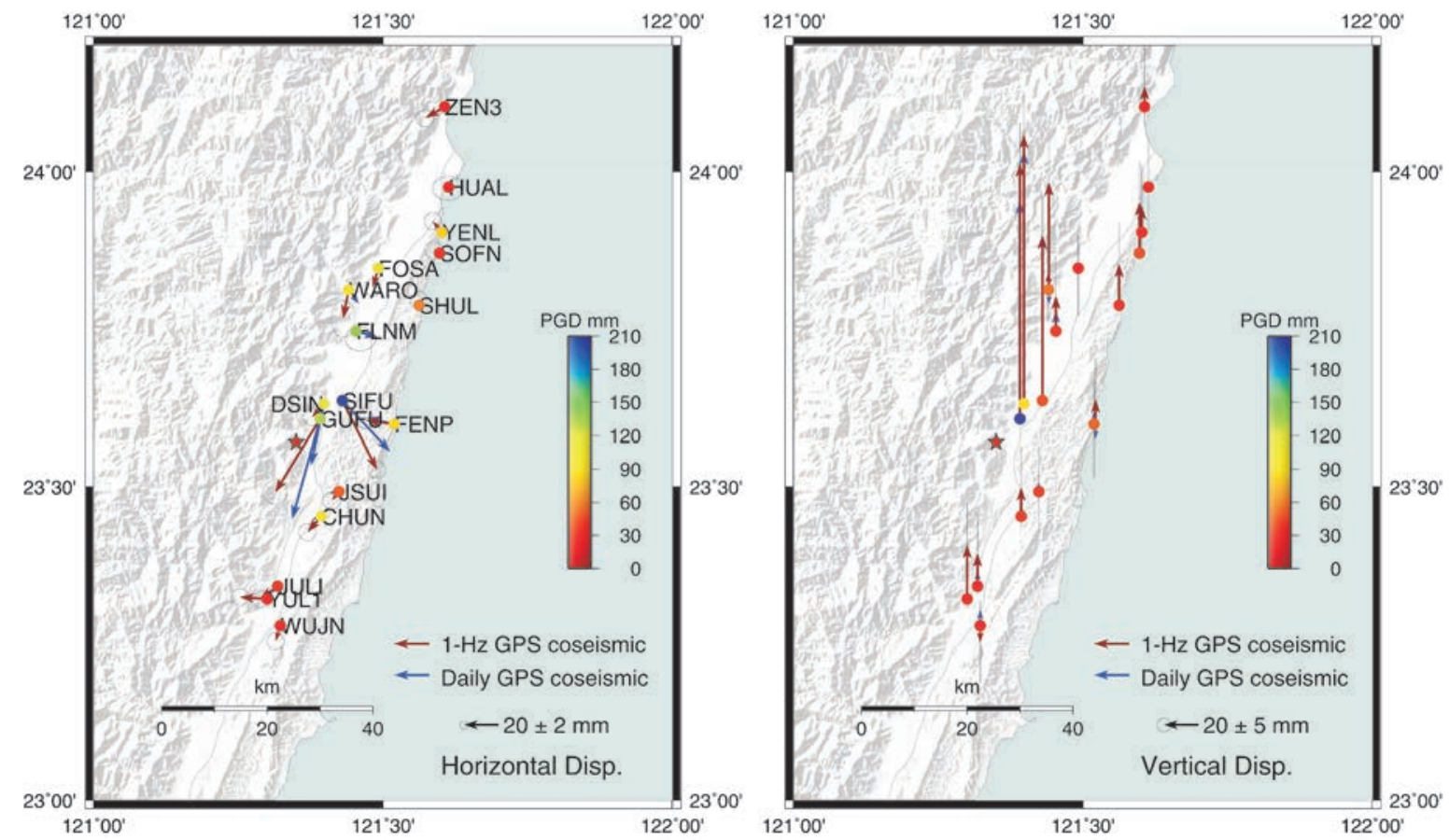

Figure 12. (a). Horizontal co-seismic displacements derived from the $1-\mathrm{Hz}$ and daily CGPS measurements. The 1-Hz displacements were determined by the difference between the coordinate averages of 100-150 seconds after the earthquake origin time and 50 seconds before the earthquake. The largest horizontal co-seismic displacement was detected at SIFU, approximately $6 \mathrm{~cm}$ toward SE. Peak Ground Displacements (PGD) of the stations are shown in horizontal and vertical components, respectively. (b). Vertical co-seismic displacements derived from the 1-Hz and daily CGPS measurements. See the figure caption of Figure 12a.

(CER), Longitudinal Valley (LV), and Coastal range (COR) (Figures 15, 16, 17). The later phases, $\sim 15$ seconds after the $S$ waves, have clearly larger amplitudes in LV than in COR and CER (where basically cannot be detected), especially in the radial component. This is also confirmed by the peak-to-peak amplitudes (Figure 18). Therefore, the joint analysis of the CGPSs and SMTs derived waveforms suggest that later phases are trapped within the Longitudinal Valley, being this likely due to the fact that this is a suture zone composed of Holocene thick sediment deposits.

\begin{tabular}{lccccc}
\hline GPS GROUND & GPS ROOF & $\begin{array}{c}\text { Latitude } \\
\text { (degree })\end{array}$ & $\begin{array}{c}\text { Longitude } \\
(\text { degree })\end{array}$ & $\begin{array}{c}\text { Inter-distance } \\
(\mathbf{k m})\end{array}$ & $\begin{array}{c}\text { Height } \\
\text { difference }(\mathbf{m})\end{array}$ \\
\hline SLIN & WARO & 23.81 & 121.44 & 0.1 & 7.6 \\
FENP & FONB & 23.60 & 121.52 & 0.2 & 11.6 \\
DSIN & GUFU & 23.62 & 121.39 & 2.8 & 37.9 \\
\hline
\end{tabular}

Table 5. Pairs of co-located (ground and roof) CGPS stations (average).

spectral analysis of the later phases, highlighting a significantly stronger energy in the frequency range $0.5-1 \mathrm{~Hz}$ within LV than in the other two regions, with $\sim 1-2.5 \mathrm{~cm}$

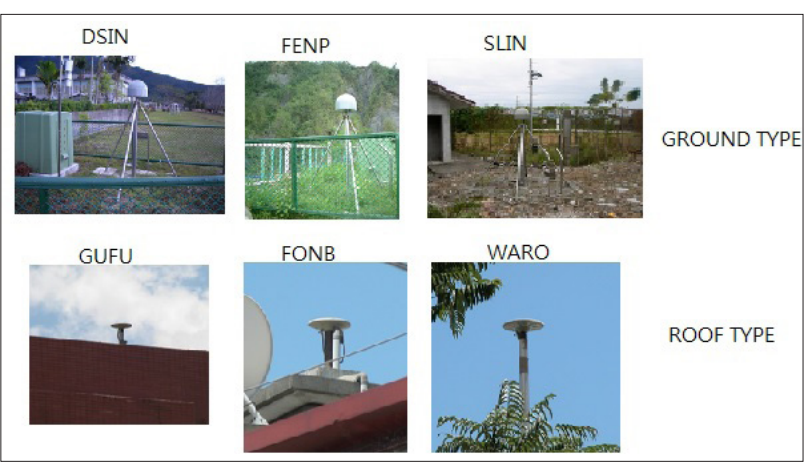

Figure 13. Examples of CGPS antennas in ground type and roof type monuments.

\section{Conclusions}

In this study, the first twelve $50-\mathrm{Hz}$, four $20-\mathrm{Hz}$ and thirteen 1-Hz CGPS epoch-by-epoch displacements in Taiwan are derived for seismological applications with respect to the 31 October 2013, $M_{L} 6.4$ Ruisui earthquake, Taiwan. The importance of GNSS seismology, better if in real-time, can be well understood considering that, even for a moderate magnitude earthquake like the Ruisui one, waveforms generated from the broadband seismometer are clipped for some of the near-field stations within $80 \mathrm{~km}$ epicentral distances. These truncated waveforms may cause severe mistakes for the estimation of the focal mechanism and the earthquake magnitude. GPS derived waveforms can provide quite useful information to compensate 


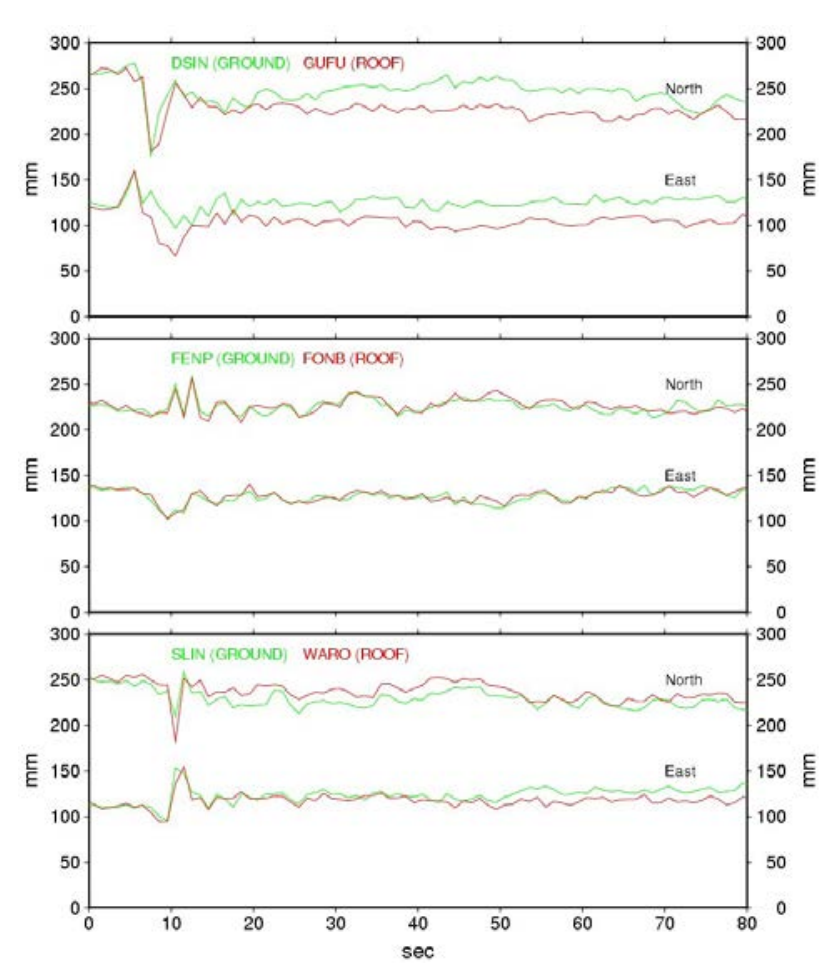

Figure 14. Comparison between approximately co-located groundtype and roof-type 1-Hz CGPSs (detailed information about these pairs are shown in Table 5 and Figure 13).

the weakness of the seismic measurements close to the epicenter; in particular, observations at sampling rate as high as $50-$ and $20-\mathrm{Hz}$ demonstrated their capability in retrieving reliable seismic waveforms for the near-fault observations.

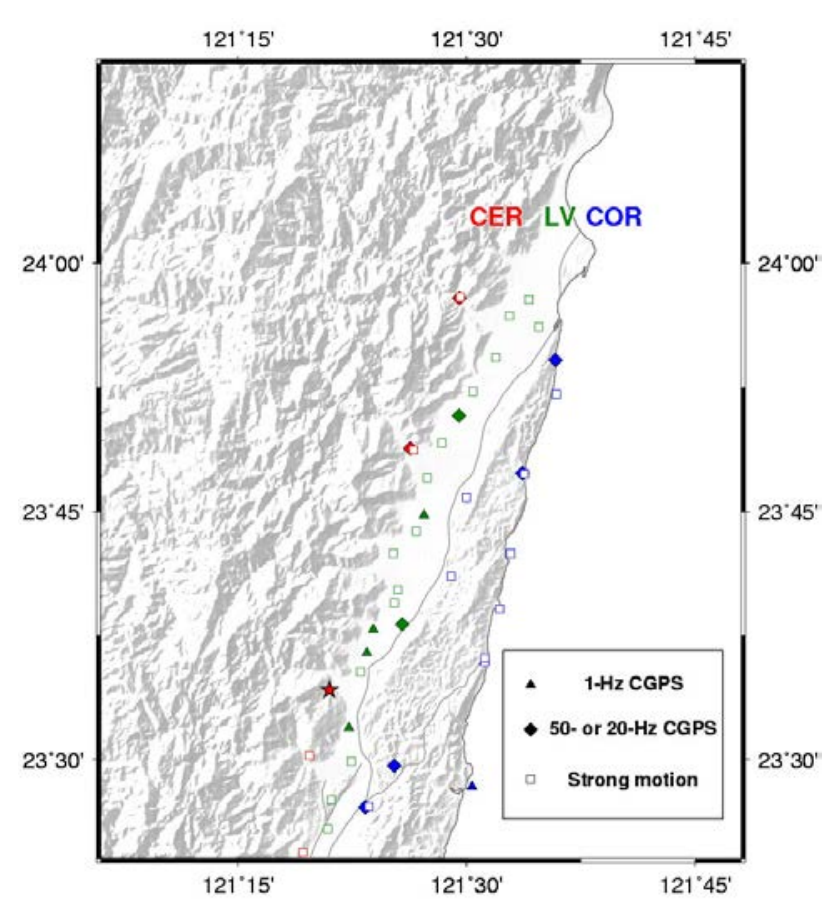

Figure 15. Location map of the 50-, 20-Hz GPS, 1-Hz GPS, and strong motion measurements at the Central Range (CER), Longitudinal Valley (LV), and Coastal Range (COS).
We used several types of positioning approaches and related software to evaluate their reliability for seismological applications. At first, results showed that the displacements estimated by PPP have a similar precision as those derived from the DP. Furthermore, the basic feature of PPP is the displacements/waveforms estimation without reference station(s); that can avoid spurious effects due to the motion of the reference station(s) required in DD approach, in case these stations are affected by the earthquake too. On the other hand, real-time PPP solution is achievable using dual-frequency (geodetic class) receivers only. Secondly, seismic displacements estimated using VADASE supplied similar waveforms in comparison with results derived using other software implementing DP and PPP approaches. The three approach solutions are consistent at the level of 1-2 centimeters in the frequency range 0.08-3 Hz. Moreover, VADASE approach supplies a more efficient data processing with respect to the $\mathrm{DD}$ and PPP, since no convergence time for initial phase ambiguities is required, so that the observations just collected during the earthquake are sufficient to provide the solution (in our case, 2 minutes instead of 2 hours observations were used). In addition, since VADASE is suitable to process single frequency observations, it actually represents a good alternative solution for the low-cost and real-time GPS seismology. On the other hand, VADASE solutions can suffer for unmodeled effects common to close CGPS, which have to be removed by a spatial filter; anyway, this requirement is not a severe drawback and can be acknowledged if (as standard) all the solutions of a CGPSs network are managed within a centralized data center.

The high-rate GPS waveforms were compared with those derived through double integration from approximately co-located SMT, within an inter-distance within 2 kilometers. A good agreement, with correlation coefficients 0.7 in the frequency span of 0.3-2 Hz, confirmed that $50-$ and $20-\mathrm{Hz}$ GPS can be an alternative with respect to accelerometers in the moderate or large earthquake. However, we found that, as expected, the accuracy of the GPS waveforms relies on the type of the monument (ground or roof); anyway, if the height above the ground is small (let say, within 10 meters), the effect is still limited, within 1-2 centimeters. This fact must be accounted for since in the urban areas of Taiwan, most of the CGPS stations are established on the roof of the buildings due to the poor GPS satellite geometry on the ground. 
CER

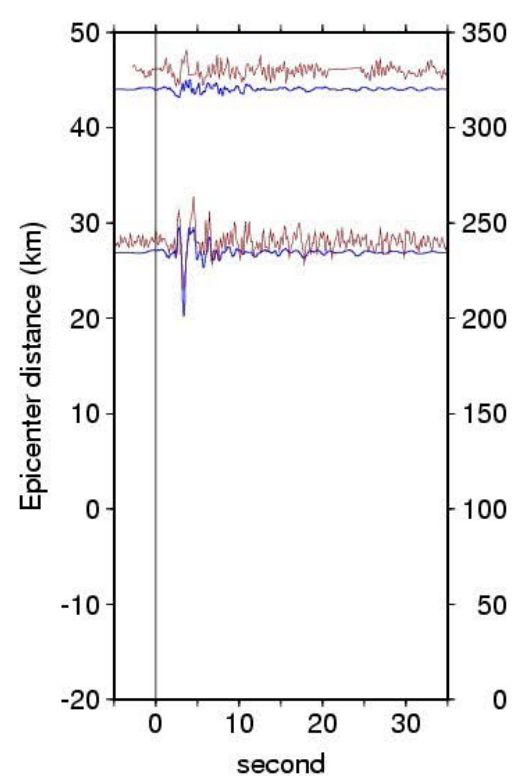

LV

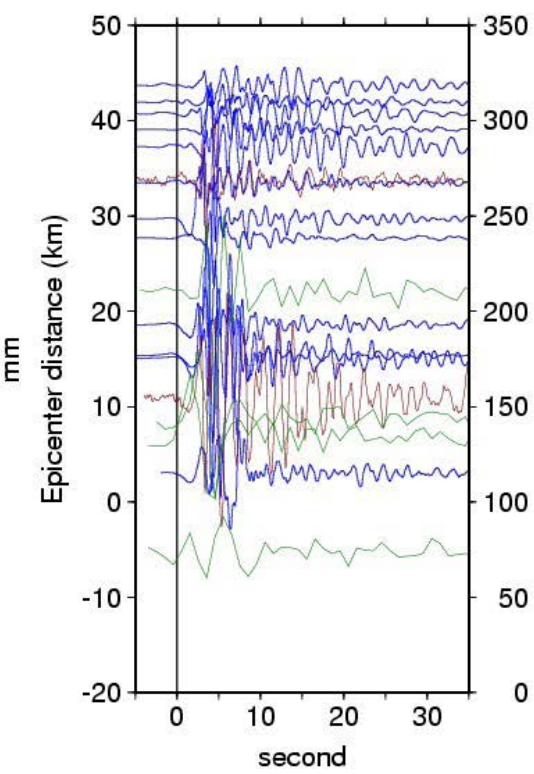

$\cos$

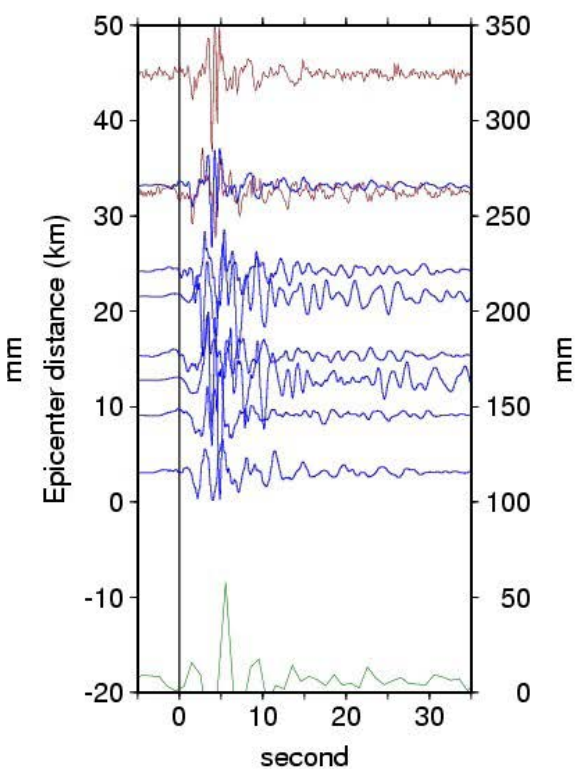

Figure 16. Seismic waves in radial component generated from resampled 10-Hz CGPS (brown), 1-Hz CGPS (green) and strong motion observations (blue) at zone CER, LV, and COS (an epicentral distance is positive northward with respect to the epicenter).

CER

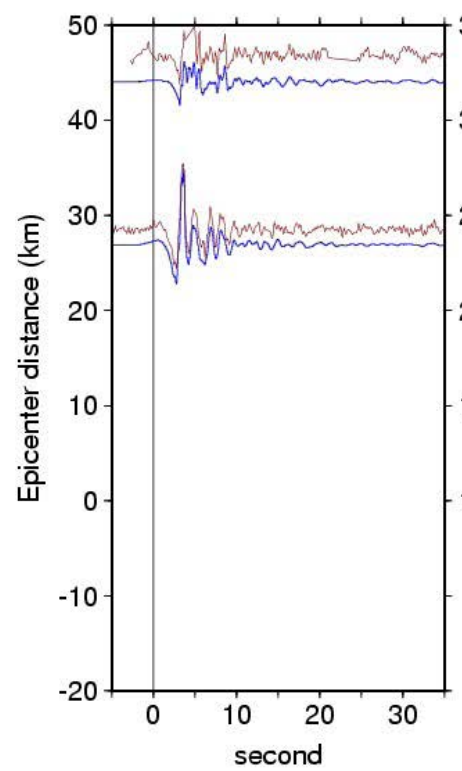

LV

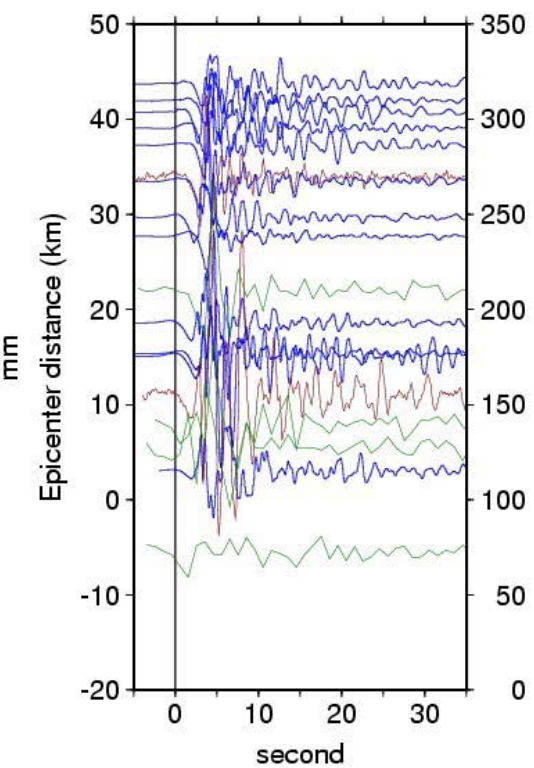

$\cos$

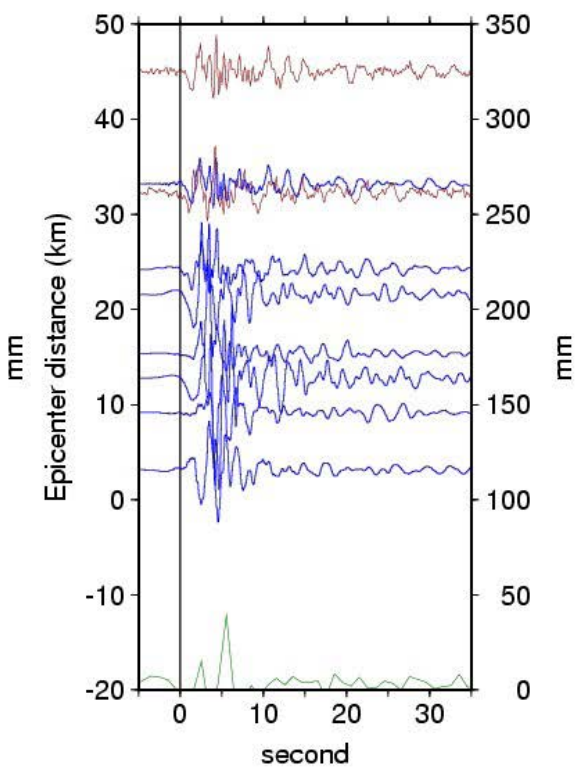

Figure 17. Seismic waves in transverse component generated from resampled 10-Hz CGPS (brown) and strong motion observations (blue) at zone CER, LV, and COS (an epicentral distance is positive northward with respect to the epicenter).

Results of spectra analysis between co-located GPS and strong motion data indicate that the ground motion sensitivity limit for GPS is about -20dB for a frequency above $2.5 \mathrm{~Hz}$, and thus we suggest that the optimal sampling rate for high-rate GPS is $5 \mathrm{~Hz}$ for seismology research, which is also shown by Galetzka et al. [2015].
The performed analyses proved that waveforms derived from 50-, 20-, and 1-Hz CGPSs and strong motions measurements are substantially coherent at very few centimeters level. Their combination was proven to be effective: when jointly analyzed for seismological interpretation, the waveforms generated from both high-rate GPS and SMT could give information about 

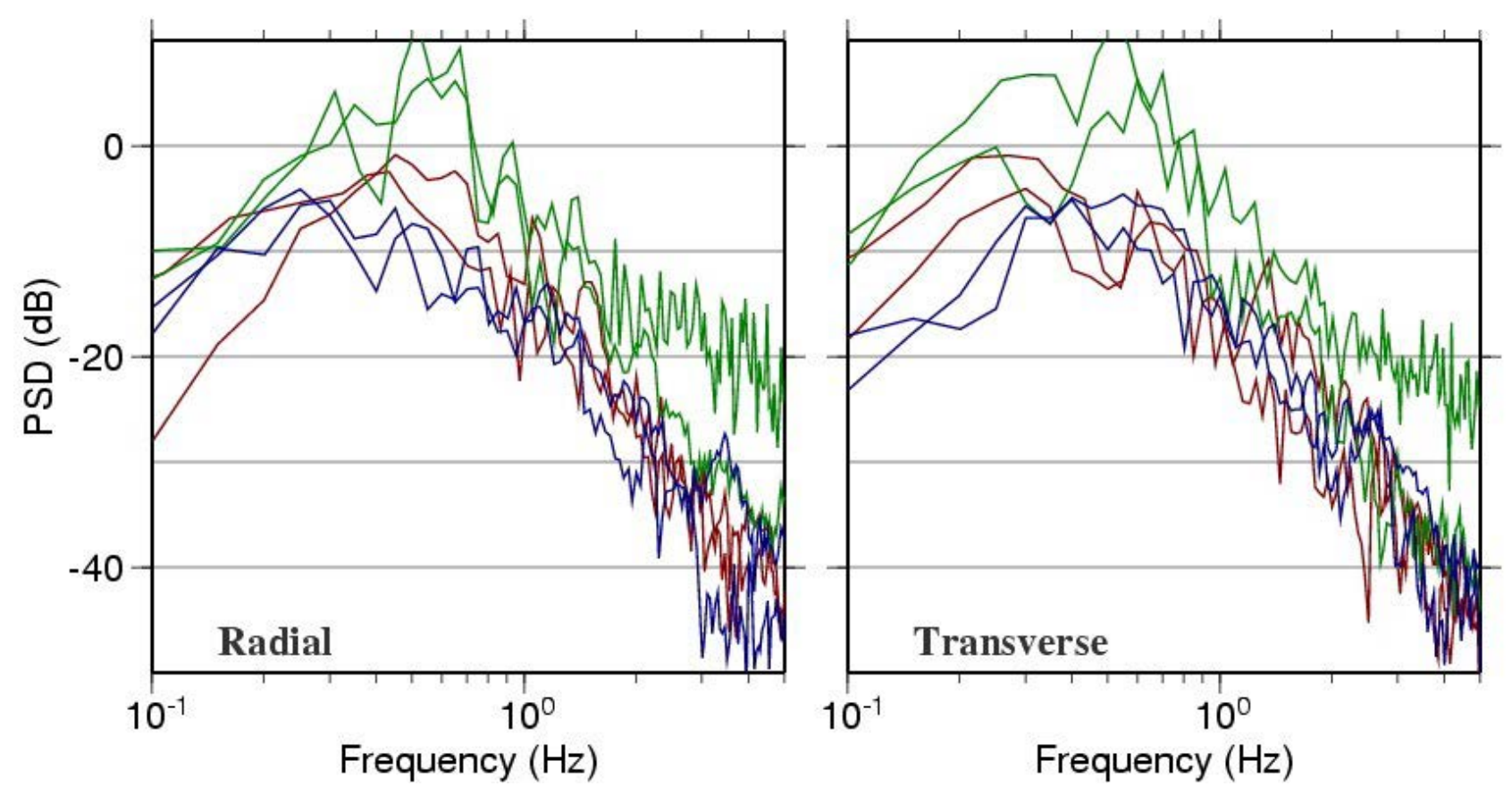

Figure 18. Power spectral density (PSD) of the seismic waveforms at the locations of the CER (brown), LV (green), and COS (blue). Note the stronger energy in the frequency range $0.5-1 \mathrm{~Hz}$ within $\mathrm{LV}$ than in the other two regions.

significant differences among various tectonic settings in eastern Taiwan (Central Range, Longitudinal Valley, and Coastal Range), where the derived waveforms suggest that later phases are trapped within the Longitudinal Valley. So, dense seismic and GPS network can contribute to more precise results for the interpretation of changing of the waveform features with different tectonic regime.

Acknowledgements. We thank Ministry of the Interior, Institute of Earth Sciences of Academia Sinica, Central Weather Bureau, and Central Geological Survey of Taiwan for the GPS data. We are grateful to Diego Melgar and one anonymous reviewer for critical comments. Figures were generated using the Generic Mapping Tools (GMT), developed by Wessel and Smith [1991]. This research was partially supported by Taiwan MOST grant 105-2116-M-006-003.

\section{References}

Avallone, A., M. Marzario, A. Cirella, A. Piatanesi, A. Rovelli, C. Di Alessandro, E. D’Anastasio, N. D’Agostino, R. Giuliani, and M. Mattone (2011), Very high rate $(10 \mathrm{~Hz})$ GPS seismology for moderate-magnitude earthquakes: The case of the Mw 6.3 L'Aquila (central Italy) event, J Geophys Res, 116, B02305, doi:10.1029/2010JB007834.

Benedetti, E., M. Branzanti, L. Biagi, G. Colosimo, A. Mazzoni, and M. Crespi (2014), Global Navigation Satellite Systems Seismology for the 2012 Mw 6.1 Emilia Earthquake: Exploiting the VADASE Algorithm, Seismol Res Lett, 85(3), 649-656.
Bilich, A., J. F. Cassidy, and K. M. Larson (2008), GPS Seismology: Application to the $2002 \mathrm{Mw} 7.9$ Denali Fault Earthquake, B Seismol Soc Am, 98(2), 593-606.

Blewitt, G., W. C. Hammond, C. Kreemer, H.-P. Plag, S. Stein, and E. Okal (2009), GPS for real-time earthquake source determination and tsunami warning systems, J Geodesy, 83(3-4), 335-343.

Bock, Y., R. M. Nikolaidis, and P. de Jonge (2000), Instantaneous geodetic positioning at medium distances with the Global Positioning System, J. Geophys. Res., 105(B12), 28,223-28,253, doi:10.1029/2000JB900268.

Bock, Y., L. Prawirodirdjo, and T. I. Melbourne (2004), Detection of arbitrarily large dynamic ground motions with a dense high-rate GPS network, Geophys Res Lett, 31(6).

Bock, Y., D. Melgar, and B. W. Crowell (2011), Real-Time strong-Motion broadband displacements from collocated GPS and accelerometers, B Seismol Soc Am, 101(6), 2904-2925.

Boore, D. M. (2010), TSPP--A collection of FORTRAN programs for processing and manipulating time series, edited, U.S. Geological Survey Open-File Report 2008-1111 (Revision 2.1).

Branzanti, M., G. Colosimo, M. Crespi, and A. Mazzoni (2013), GPS Near-Real-time Coseismic Displacements for the Great Tohoku-oki Earthquake, Geoscience and Remote Sensing Letters, IEEE, 10(2), 372-376. 
Choi, K., A. Bilich, K. M. Larson, and P. Axelrad (2004), Modified sidereal filtering: Implications for highrate GPS positioning, Geophys. Res. Lett., 31, L22608, doi:10.1029/2004GL021621.

Colosimo, G., M. Crespi, and A. Mazzoni (2011a), Real-time GPS seismology with a stand-alone receiver: A preliminary feasibility demonstration, Journal of Geophysical Research: Solid Earth, 116(B11), B11302.

Colosimo, G., M. Crespi, A. Mazzoni and T. Dautermann (2011b). Co-seismic displacement estimation: Improving tsunami early warning systems. GIM International, 25(5).

Crowell, B. W., Y. Bock, and M. B. Squibb (2009), Demonstration of earthquake early warning using total displacement waveforms from real-time GPS networks, Seismol Res Lett, 80(5), 772-782.

Davis, J. P., and R. Smalley (2009), Love wave dispersion in central North America determined using absolute displacement seismograms from high-rate GPS, J Geophys Res-Sol Ea, 114.

Galetzka, J., D. Melgar, J. F. Genrich, J. Geng, S. Owen, E. O. Lindsey, X. Xu, Y. Bock, J.-P. Avouac, L. B. Adhikari, B. N. Upreti, B. Pratt-Sitaula, T. N. Bhattarai, B. P. Sitaula, A. Moore, K. W. Hudnut, W. Szeliga, J. Normandeau, M. Fend, M. Flouzat, L. Bollinger, P. Shrestha, B. Koirala, U. Gautam, M. Bhatterai, R. Gupta, T. Kandel, C. Timsina, S. N. Sapkota, S. Rajaure, and N. Maharjan (2015), Slip pulse and resonance of the Kathmandu basin during the 2015 Gorkha earthquake, Nepal, Science, 349(6252), 1091-1095.

Grandin, R., M. Vallée, C. Satriano, R. Lacassin, Y. Klinger, M. Simoes, and L. Bollinger (2015), Rupture process ofthe $\mathrm{Mw}=7.92015$ Gorkha earthquake(Nepal): Insights into Himalayan megathrust segmentation, Geophys. Res. Lett., 42,8373-8382, doi:10.1002/2015GL066044.

Grapenthin, R., and J. T. Freymueller (2011), The dynamics of a seismic wave field: Animation and analysis of kinematic GPS data recorded during the 2011 Tohokuoki earthquake, Japan, Geophys Res Lett, 38(18).

Herring, T. A. (2009), TRACK GPS kinematic positioning program, edited, Cambridge.

Hofmann-Wellenhof, B., H. Lichtenegger, and J. Collins (2006), Global Positioning System, edited, Springer.

Hung, H. K., and R. J. Rau (2013), Surface waves of the 2011 Tohoku earthquake: Observations of Taiwan's dense high-rate GPS network, J Geophys Res-Sol Ea, 118(1), 332-345.
Kouba, J. (2003), Measuring seismic waves induced by large earthquakes with GPS, Stud. Geophys. Geod., 47(4), 741-755, doi:10.1023/ A:1026390618355.

Kouba, J. (2005), A possible detection of the 26 December 2004 Great Sumatra-Andaman Islands Earthquake with solution products of the International GNSS Service, Stud. Geophys. Geod., 49, 463-483, doi:10.1007/s11200-005-0022-4.

Langbein, J., and Y. Bock (2004), High-rate real-time GPS network at Parkfield: Utility for detecting fault slip and seismic displacements, Geophys. Res. Lett., 31, L15S20, doi:10.1029/2003GL019408.

Larson, K. M. (2009), GPS seismology, J Geodesy, 83(34), 227-233.

Larson, K., A. Bilich, and P. Axelrad (2007), Improving the precision of high-rate GPS, J. Geophys. Res., 112, B05422, doi:10.1029/2006JB004367.

Larson, K. M., P. Bodin, and J. Gomberg (2003), Using 1-Hz GPS Data to Measure Deformations Caused by the Denali Fault Earthquake, Science, 300(5624), 1421-1424.

Larson, K., and S. Miyazaki (2008), Resolving static offsets from high-rate GPS data: The 2003 Tokachi-oki earthquake, Earth Planets Space, 60, 801-808.

Lee, S. J., H. H. Huang, J. B. H. Shyu, T. Y. Yeh, and T. C. Lin (2014), Numerical earthquake model of the 31 October 2013 Ruisui, Taiwan, earthquake: Source rupture process and seismic wave propagation. J. Asian Earth Sci., 96, 374-385, doi: 10.1016/j. jseaes.2014.09.020.

Li, X., M. Ge, X. Zhang, Y. Zhang, B. Guo, R. Wang, J. Klotz, and J. Wickert (2013), Real-time high-rate co-seismic displacement from ambiguity-fixed precise point positioning: Application to earthquake early warning, Geophys. Res. Lett., 40, 295-300.

Li, X., M. Ge, C. Lu, Y. Zhang, R. Wang, J. Wickert, and H. Schuh (2014a), High-Rate GPS Seismology Using Real-Time Precise Point Positioning With Ambiguity Resolution, Geoscience and Remote Sensing, IEEE Transactions on, 52(10), 6165-6180.

Li, X., B. Guo, C. Lu, M. Ge, J. Wickert, H. Schuh (2014b), Real-time GNSS seismology using a single receiver, Geophysical Journal International, 198, 1, 72

Lou, Y. D., W. X. Zhang, C. Shi, and J. N. Liu (2014), High-rate (1-Hz and $50-\mathrm{Hz}$ ) GPS seismology: Application to the $2013 \mathrm{M}-\mathrm{w}$ 6.6 Lushan earthquake, J Asian Earth Sci, 79, 426-431.

Melgar, D., and Y. Bock (2015), Kinematic earthquake source inversion and tsunami runup prediction with regional geophysical data, J. Geophys. Res. Solid Earth, 120, 3324-3349, doi:10.1002/2014JB011832. 
Melgar, D., Y. Bock, D. Sanchez, and B. W. Crowell (2013), On robust and reliable automated baseline corrections for strong motion seismology, Journal of Geophysical Research: Solid Earth, 118(3), 1177-1187.

Melgar, D., and Y. Bock (2015), Kine-matic earthquake source inversionand tsunami runup prediction withregional geophysical data, J. Geophysical Research: Solid Earth, 120, 3324-3349, doi:10.1002/ 2014JB011832.

Miyazaki, S., and K. Larson (2008), Coseismic and early postseismic slip for the 2003 Tokachi-oki earthquake sequence inferred from GPS data, Geophys. Res. Lett., 35, L04302, doi:10.1029/2007GL032309.

Ohta, Y., I. Meilano, T. Sagiya, F. Kimata, and K. Hirahara (2006), Large surface wave of the 2004 Sumatra-Andaman earthquake captured by the very long baseline kinematic analysis of 1-Hz GPS data, Earth Planets Space, 58(2), 153.

Ohta, Y., T. Kobayashi, H. Tsushima, S. Miura, R. Hino, T. Takasu, H. Fujimoto, T. Iinuma, K. Tachibana, and T. Demachi (2012), Quasi real-time fault model estimation for near-field tsunami forecasting based on RTK-GPS analysis: Application to the 2011 Tohoku-Oki earthquake (Mw 9.0), Journal of Geophysical Research: Solid Earth (1978-2012), 117(B2).

Shi, C., Y. Lou, H. Zhang, Q. Zhao, J. Geng, R. Wang, R. Fang, and J. Liu (2010), Seismic deformation of the Mw 8.0 Wenchuan earthquake from high-rate GPS observations, Adv Space Res, 46(2), 228-235.

Smalley, R.Jr. (2009), High-rate GPS: How high do we need to go? Seismol. Res. Lett., 80, 1054-1061, doi:10.1785 / gssrl.80.6.1054.

Takasu, T. (2011), RTKLIB: An Open Source Program Package for GNSS Positioning.

Wdowinski, S., Y. Bock, J. Zhang, P. Fang, and J. Genrich (1997), Southern California Permanent GPS Geodetic Array: Spatial filtering of daily positions for estimating coseismic and postseismic displacements induced by the 1992 Landers earthquake, J. Geophys. Res., 102(B8), 18057-18070.

Wen, Y.-Y., Y.-T. Yen, S. Wen, S.-J. Lee, C.-H. Kuo, and Y.-Y. Lin (2016), Hybrid ground motion simulation for the $2013 \mathrm{M}_{\mathrm{L}} 6.4$ Ruisui, Taiwan earthquake, Terr. Atmos. Ocean. Sci., 27, 3, 407-414.

Wessel, P., and W. Smith (1991), Free software helps map and display data, Eos Trans. AGU, 72 (441), 445-446.

Yeh, T., B. Chao, C. Chen, C. Chen, and Z. Lee (2012), Performance improvement of network based RTK GPS positioning in Taiwan, Surv Rev, 44(324), 3-8.

Yin, H., and S. Wdowinski (2013), Improved detection of earthquake-induced ground motion with spatial filter: case study of the $2012 \mathrm{M}=7.6$ Costa Rica earthquake, GPS Solutions, 1-8.

Zheng, Y., J. Li, Z. Xie, and M. H. Ritzwoller (2012), $5 \mathrm{~Hz}$ GPS seismology of the El Mayor-Cucapah earthquake: estimating the earthquake focal mechanism, Geophys J Int, 190(3), 1723-1732.

Zumberge, J. F., M. B. Heflin, D. C. Jefferson, M. M. Watkins, and F. H. Webb (1997), Precise point positioning for the efficient and robust analysis of GPS data from large networks, Journal of Geophysical Research: Solid Earth, 102(B3), 5005-5017.
${ }^{\star}$ Corresponding author: Ruey-Juin Rau Department of Earth Sciences, National Cheng Kung University, Tainan, Taiwan; email: raurj@mail.ncku.edu.tw

2017 by Istituto Nazionale di Geofisica e Vulcanologia. All rights reserved 